\title{
ENSO in the Mid-Holocene according to CSM and HadCM3
}

\author{
WiLLIAM H. G. ROBERTS \\ University of Bristol, Clifton, Bristol, United Kingdom \\ DAVID S. BATTISTI \\ University of Washington, Seattle, Washington \\ ALEXANDER W. TUDHOPE \\ University of Edinburgh, Edinburgh, Scotland
}

(Manuscript received 22 April 2013, in final form 18 September 2013)

\begin{abstract}
The offline linearized ocean-atmosphere model (LOAM), which was developed to quantify the impact of the climatological mean state on the variability of the El Niño-Southern Oscillation (ENSO), is used to illuminate why ENSO changed between the modern-day and early/mid-Holocene simulations in two climate modeling studies using the NCAR Climate System Model (CSM) and the Hadley Centre Coupled Model, version 3 (HadCM3). LOAM reproduces the spatiotemporal variability simulated by the climate models and shows both the reduction in the variance of ENSO and the changes in the spatial structure of the variance during the early/mid-Holocene. The mean state changes that are important in each model are different and, in both cases, are also different from those hypothesized to be important in the original papers describing these simulations. In the CSM simulations, the ENSO mode is stabilized by the mean cooling of the SST. This reduces atmospheric heating anomalies that in turn give smaller wind stress anomalies, thus weakening the Bjerknes feedback. Within the ocean, a change in the thermocline structure alters the spatial pattern of the variance, shifting the peak variance farther east, but does not reduce the overall amount of ENSO variance. In HadCM3, the ENSO mode is stabilized by a combination of a weaker thermocline and weakened horizontal surface currents. Both of these reduce the Bjerknes feedback by reducing the ocean's SST response to wind stress forcing. This study demonstrates the importance of considering the combined effect of a mean state change on the coupled ocean-atmosphere system: conflicting and erroneous results are obtained for both models if only one model component is considered in isolation.
\end{abstract}

\section{Introduction}

There is a large body of evidence suggesting that, during the early to mid-Holocene [6-10 thousand years before present (6-10 ka)], the El Niño-Southern Oscillation (ENSO) was weaker than at present [see Braconnot et al. (2011) for a summary of these data]. Proxy data of SST and precipitation variability from throughout the equatorial Pacific suggest that the interannual variance in SST in the early and mid-Holocene was reduced by $20 \%$ to as much as $80 \%$ when compared

Corresponding author address: William H. G. Roberts, School of Geographical Sciences, University of Bristol, University Road, Clifton, Bristol BS8 1SS, United Kingdom.

E-mail: William.Roberts@bristol.ac.uk to today, although Cobb et al. (2013) illustrate the challenges of identifying any systematic trends through the mid- to late Holocene due to the high internal variability in variance. Since the overwhelming share of interannual variance in the equatorial Pacific today is due to ENSO, we can assume that ENSO variance in the early Holocene was likely reduced compared to the modern climate.

Several modeling studies have been performed to examine the ENSO in the early (8.5 ka) and mid- $(6 \mathrm{ka})$ Holocene. Each of these studies reported reduced ENSO activity in their early and mid-Holocene simulations compared to the modern-day integrations, although the metric used to measure ENSO and the size of the reduction varies greatly across these studies. These results are summarized in Table 1. 
TABLE 1. The change in Niño-3 variance reported in modeling studies of the mid-Holocene (6 ka) and modern day. Column two shows the reduction in Niño-3 variance in the mid-Holocene compared to the variance in the modern-day simulation. The third column contains the original hypothesis offered for the change in ENSO in that study. The fourth column contains some additional comments. Reduced variance amounts for the HadCM3 and CSM models differ from those quoted throughout the text because the set of years we have analyzed in the current study are somewhat different from those analyzed in the original papers.

\begin{tabular}{|c|c|c|c|}
\hline Model (reference) & Change in Niño-3 variance & Original hypothesis & Further comments \\
\hline ZCM (Clement et al. 2000) & $\begin{array}{l}\text { Smaller amplitude, less } \\
\text { frequent warm and } \\
\text { cold events }\end{array}$ & $\begin{array}{l}\text { Decreased instability in the ENSO } \\
\text { mode due to enhanced trades } \\
\text { and changed seasonality }\end{array}$ & $\begin{array}{l}\text { Nonlinear saturation/ENSO mode } \\
\text { is more unstable (see Roberts } \\
\text { 2007) }\end{array}$ \\
\hline $\begin{array}{l}\text { Fast Ocean Atmosphere } \\
\text { Model (FOAM) (Liu } \\
\text { et al. 2000) }\end{array}$ & $-20 \%$ & $\begin{array}{l}\text { Increased stability of the ENSO } \\
\text { mode due to weakened } \\
\text { thermocline }\end{array}$ & \\
\hline $\begin{array}{l}\text { CSM, version } 1.4 \text { (CSM1.4) } \\
\quad \text { (Otto-Bliesner et al. 2003) }\end{array}$ & $-22 \%(-28 \%$ for $8.5 \mathrm{ka})$ & $\begin{array}{l}\text { Increased stability in the ENSO } \\
\text { mode due to weakened } \\
\text { thermocline }\end{array}$ & $\begin{array}{l}\text { Increased stability in the ENSO } \\
\text { mode due to stabilized } \\
\text { atmosphere (this study) }\end{array}$ \\
\hline HadCM3 (Brown et al. 2008) & $-24 \%$ & $\begin{array}{l}\text { Increased stability in the ENSO } \\
\text { mode due to enhanced trades } \\
\text { and changed seasonality }\end{array}$ & $\begin{array}{l}\text { Increased stability in the ENSO } \\
\text { mode due to weaker thermocline } \\
\text { and zonal currents (this study) }\end{array}$ \\
\hline $\begin{array}{l}\text { PMIP phase } 2 \text { (PMIP2) } \\
\text { (Zheng et al. 2008) }\end{array}$ & +3.3 to $-22.5 \%$ & $\begin{array}{l}\text { Increased stability in the ENSO } \\
\text { mode due to enhanced trades } \\
\text { and changed seasonality }\end{array}$ & \\
\hline $\begin{array}{l}\text { Community Atmosphere } \\
\text { Model and Reduced-Gravity } \\
\text { Ocean (CAM + RGO) } \\
\text { (Chiang et al. 2009) }\end{array}$ & $-38 \%$ & $\begin{array}{l}\text { Reduction in the amplitude of } \\
\text { stochastic forcing from the } \\
\text { extratropics }\end{array}$ & \\
\hline $\begin{array}{l}\text { L'Institut Pierre-Simon } \\
\text { Laplace Coupled Model, } \\
\text { version } 4 \text { (IPSL-CM4) } \\
\text { (Braconnot et al. 2011) }\end{array}$ & $\begin{array}{l}\text { Fewer warm and cold } \\
\text { events at } 6 \text { and } 9.5 \mathrm{ka}\end{array}$ & $\begin{array}{l}\text { Increased stability in the ENSO } \\
\text { mode due to enhanced trade } \\
\text { winds }\end{array}$ & \\
\hline
\end{tabular}

Although the changes in insolation were the root cause of the reduction in ENSO variance in the early and mid-Holocene in all of the aforementioned studies, there is, as yet, little consensus on the processes responsible. Three hypotheses have been put forward. The first, and most frequently invoked, is that proposed by Clement et al. (2000): ENSO variance is reduced because changes in the climatological mean state of the tropical Pacific atmosphere-ocean system render the ENSO eigenmode less unstable than in the modern climate (hypothesis A). In their model, Clement et al. identified that the changes in the climatological mean state that were most important were the enhanced trade winds and their changed seasonality owing to processes that are intrinsic to the equatorial Pacific [the Zebiak-Cane model (ZCM) is a regional model of the atmosphere-ocean system exclusively within the equatorial Pacific]. Related to this is the idea of a frequency entrainment in which changes in the strength of the seasonal cycle can, through nonlinearities in the system, alter the stability of ENSO (Liu 2002). In contrast, Liu et al. (2000) argued that changes in the mean state of the thermocline along the equator stabilize the ENSO mode and they hypothesized that this was likely the source of the reduced variance of ENSO in their model (hypothesis B). They proposed that changes in the water subducted into the thermocline from the South Pacific subtropical gyre reduce the effect of upwelling on SST. More recently Chiang et al. (2009) and Chiang and Fang (2010) proposed that the source of the reduced ENSO variability in their model was a change in the weather in the extratropical Northern Hemisphere that supplies the (noise) forcing that excites ENSO in their model [and in nature, Vimont et al. (2003)] (hypothesis C). Of these three mechanisms only hypothesis $\mathrm{C}$ has been conclusively shown to be the cause of the reduced ENSO variability in the model: neither hypothesis A nor B has yet been formally tested in any model.

Subsequent studies have hypothesized that mechanisms similar to hypotheses A and B are at work in their particular model by noting similarities between changes in the mean state of their model and the mean state changes held to be responsible in A and B. Otto-Bliesner et al. (2003) reported mean state changes in their model that were similar to those found by Liu et al. (2000) so they invoked the latter's hypothesis B as a possible cause for the reduction of ENSO variance in their model. Similarly, Brown et al. (2008) and Zheng et al. (2008) reported mean-state changes to the trade winds in their models that were similar to those found by Clement et al. (2000), so they invoked the latter's hypothesis A to explain the reduction of ENSO variance. 
The studies by Liu et al. (2000), Otto-Bliesner et al. (2003), Zheng et al. (2008), and Brown et al. (2008) used full climate models, that is, models that include an atmosphere and ocean general circulation model (GCM). Since these models calculate both the mean state and the variability, it is difficult to disentangle the impact of one upon the other. It is possible to note simultaneous correlations between them but extremely difficult to demonstrate that some change in the mean state was responsible for the change in ENSO variability (or vice versa). It is difficult, if not impossible, to design GCM experiments to test such a hypothesis. Similarly, the ZCM used in the Clement et al. (2000) study is a regional model that precludes the possibility of any impact from outside the Pacific basin [the same processes shown to be important in the study of Chiang et al. (2009)]: it contains linearized ocean dynamics and, thus, does not include the physics responsible for determining the climatological thermocline in the deep tropics. Only a GCM contains all of the necessary components to avoid all of these shortcomings, but as we have said, the complexity of a GCM makes it exceptionally difficult to analyze.

There is, therefore, a gap between the GCMs that offer a complete description of the climate, but can never give us a mechanistic understanding of ENSO, and the intermediate models that can tell us a lot about ENSO but are unable to completely respond to the changes in forcing. In this study, we bridge this gap by using the mean state from a GCM, which gives the full physical response to changes in forcing and a reducedphysics model of ENSO. If the reduced physics model of ENSO can faithfully reproduce the GCM's ENSO using the GCM mean states, then we can use it to deduce which of the mean state changes in the early/midHolocene was responsible for the changes in ENSO in the GCM. In this way, we combine the completeness of the GCM with the tractability of the simple ENSO model.

The GCMs that we shall use are the National Center for Atmospheric Research Climate System Model (CSM) (Otto-Bliesner and Brady 2001; Otto-Bliesner et al. 2003) and Hadley Centre Coupled Model, version 3 (HadCM3) (Brown et al. 2006). These GCMs have been shown to simulate reductions in ENSO variability during the early Holocene that are comparable to that observed. The ENSO model that we use is the offline linearized ocean-atmosphere model (LOAM) - a coupled oceanatmosphere model system in the tropical Pacific that has been shown to accurately capture the behavior of ENSO in nature when given the present-day observed mean states (Roberts and Battisti 2011).

The paper proceeds as follows. In section 2, we describe the basis of the offline model LOAM that we will use to diagnose the GCMs and detail the procedure for incorporating mean-state data into it. In section 3, we summarize the climatological mean state and the ENSO variability that are featured in the present-day and early Holocene simulations of the Community Climate System Model (CCSM) and use LOAM to diagnose the processes responsible for the orbitally induced changes in the structure and variance of ENSO as simulated by this climate model. In section 4 , we perform the same analysis as in section 3, only on the output of the preindustrial and early Holocene integrations from HadCM3. A discussion of previous hypotheses for reduced ENSO in light of our results is presented in section 5, and conclusions and implications are presented in section 6 .

\section{The analysis tool: LOAM}

In this section, we describe the tool that we use to analyze the coupled atmosphere-ocean variability in the full climate models: LOAM. LOAM is a linearized variant of the coupled ocean-atmosphere model originally introduced by Zebiak and Cane (1987). We will describe how we use LOAM to diagnose the spatiotemporal properties of the ENSO mode in the fully coupled climate models.

\section{a. Introduction to LOAM}

The original Zebiak and Cane (1987) model is a coupled atmosphere-ocean model of the tropical Pacific that is formulated about a prescribed monthly varying mean state. Battisti and Hirst (1989) noticed that ENSO in the ZCM could be well described by only linear processes, which led Thompson and Battisti (2000) to introduce a linearized variant of the ZCM (Battisti 1988; Battisti and Hirst 1989), hereafter called LOAM. They showed that the leading (least damped) Floquet mode of LOAM contained the spatial and temporal properties associated with the canonical ENSO, including the evolution of sea surface temperature (SST) and the thermocline (see, e.g., Johnson et al. 2000). ${ }^{1}$ Hence, they referred to the leading Floquet mode as the "ENSO mode." Thompson and Battisti (2001) showed that, when the observed values for the efficiency of the western boundary reflection were included in the model, the ENSO mode was rendered stable and had a decay rate similar to that observed (Johnson et al. 2000) and that the basic properties of the ENSO mode were retained. They also showed that when LOAM was stochastically forced by white noise, it was able to reproduce many of

\footnotetext{
${ }^{1}$ The Floquet modes of this system are the eigenmodes of the (cyclostationary) annual propagator matrix. The period and decay rate of each eigenmode is given by the associated eigenvalue.
} 
the statistical properties associated with the observed tropical Pacific atmosphere-ocean system (which are dominated by ENSO), including the coordination of the ENSO mode with the annual cycle and the power spectrum and the seasonal dependence of autocorrelation in the Niño-3 index.

Roberts and Battisti (2011) described a system whereby the observed climatological mean-state currents and upwelling can be imported into LOAM, and the subsurface ocean parameterizations required by LOAM can be calculated. They showed that, when the mean states and subsurface temperature parameterizations are derived from observations and incorporated into LOAM, the leading Floquet mode retains all of the features of the observed ENSO mode discussed above. They also found that, when the observed mean state fields were incorporated into LOAM and the model was stochastically forced, LOAM was able to reproduce the spatiotemporal properties of tropical Pacific atmosphere-ocean variability that are robustly defined from historical data (e.g., the EOFs and the spectrum of Niño-3).

LOAM can also be used to analyze ENSO in a GCM. Using mean states derived from the GCM we can apply the same procedure as for the observations to diagnose the structure of ENSO in the GCM. The application of LOAM to the GCMs does assume that ENSO is well described by linear physics about a prescribed climatological annual cycle and forced stochastically by noise (e.g., uncoupled weather in the atmosphere and/or ocean). Although a number of analyses and model results show that the observed ENSO is well captured by linear processes [see, e.g., Thompson and Battisti (2001) and references therein], studies using intermediate coupled models and/or general circulation models find that ENSO-like variability can also occur via nonlinear dynamics that are precluded in LOAM [see section 6.2 of Neelin et al. (1998) for a brief discussion of a catalog of nonlinear hypotheses published prior to 1998, as well as the more recent studies by Liu (2002) and Timmermann et al. (2003)].

In this paper we use LOAM to diagnose the physics of the tropical Pacific atmosphere-ocean variability in the modern-day and early Holocene simulations from the CSM and HadCM3 GCMs. We then use LOAM to determine the quantitative impact of the mean state changes on the ENSO variance in the early Holocene simulations of these two models. We use the same system described in Roberts and Battisti (2011) to incorporate the climatological mean fields from the GCMs into LOAM. A brief qualitative description of this system follows in the next section. For a fuller description please see Roberts and Battisti (2011).

\section{b. Fitting LOAM to a GCM}

The time-varying climatological mean states required by LOAM are SST, surface winds, and the upper 50-m ocean currents. These are calculated from a long integration of the GCM and then interpolated onto the LOAM model grid. For each field monthly averaged values are used to represent the annual cycle of each quantity. The LOAM equation that calculates SST anomalies includes anomalous horizontal advection and two terms that account for changes in SST owing to anomalous vertical temperature advection and entrainment. These two terms are

(i) the anomalous upwelling acting on the mean vertical temperature gradient $T_{z}$ just below the base of the $(50 \mathrm{~m})$ mixed layer; and

(ii) the entrainment of temperature anomalies just below the base of the mixed layer $T_{s}$ by mixing and upwelling.

The parameterization of these vertical advection terms are calculated following a method set out by Seager et al. (1988), which is briefly described here. Both of these parameterizations vary over longitude but are constant over latitude and time.

In (i), the mean vertical gradient of temperature at the base of the mixed layer, $T_{z}$, is calculated as the annualmean temperature gradient at 50-m depth in the GCM.

Term (ii) is more complicated as it simulates how movements in the thermocline affect the temperature at the base of the mixed layer. We first derive an empirical function that maps $T_{s}$ (the temperature anomalies at the base of the mixed layer) to the thermocline depth (the depth of the $20^{\circ} \mathrm{C}$ isotherm) in the GCM. Then we derive another that maps the GCM thermocline depth (again the $20^{\circ} \mathrm{C}$ isotherm) to the LOAM model layer interface depth. These quantities are derived from seasonal cycles of the GCM and from the ZCM ocean model forced by the seasonal cycle of wind stress from the GCM. The parameterizations themselves, however, do not vary seasonally. The linearization of the product of these two empirical functions, which we shall call $\Gamma$, gives the best fit of the mapping of $T_{s}$ to the LOAM layer interface. We note that $\Gamma$ is insensitive to the choice of the isotherm used to describe the thermocline. Here we use the $20^{\circ} \mathrm{C}$ isotherm but could equally well use any other isotherm that is within the thermocline.

Along with these two parameterizations there are three coefficients used in LOAM that must be tuned using the output of the GCM. These coefficients represent processes that LOAM cannot resolve and are model dependent. Two of these coefficients are in the ocean component of the model and one in the atmosphere. In 
the ocean model, they represent the efficiency by which upwelling affects the mixed layer temperature: this efficiency is spatially and GCM dependent. These coefficients are determined by taking the anomalous wind stress from a long integration of the GCM (where anomalies are about the climatological mean state of the GCM) and finding the parameter values that minimize the least squares differences between the anomalies in SST from the GCM and those that are produced by the ocean component of LOAM when it is forced by the anomalous wind stress from the GCM.

The third coefficient is the atmospheric drag coefficient, which is calculated in a similar vein: forcing the atmosphere component of LOAM with the SST anomalies from the GCM and then scaling the drag coefficient in LOAM to maximize the least squares fit between surface wind stress anomalies in the GCM to those in LOAM. This fit is needed because the simple NigamGill model atmosphere used in LOAM calculates the wind speed averaged over the whole boundary layer, whereas the surface wind stress is needed to force the ocean model in LOAM.

After the atmosphere and ocean components of LOAM have been independently tuned they are then coupled. By independently tuning the two model components prior to coupling we do not impose any assumptions on the coupled behavior of the LOAM. This means that any change in the coupled response of the model, arising from the use of different mean states, is solely the result of the changes in the mean state and not the result of change in any a priori assumptions about the coupled behavior of the model. These three coefficients are tuned using the output from the modern-day GCM simulations. They are held constant for all subsequent experiments using LOAM, including those using the output from the early/mid-Holocene experiments. In essence we assume that these coefficients represent the different dynamical configuration of each model and are, therefore, assumed to be independent of small mean state changes, such as the difference between the early/mid-Holocene and the modern climate. Thus, in all LOAM experiments that we present, the changes to ENSO and to the mix of processes that govern ENSO in LOAM (e.g., the strength of the Bjerknes feedback) are solely due to changes in the mean state fields. Since the two GCMs we analyze are fundamentally different, we tune the two models individually to create model-specific parameters.

A complete description for fitting LOAM to a GCM is contained within Roberts and Battisti (2011). Throughout the text whenever we refer to the "mean state" we refer to the time-varying mean state that LOAM uses. Hence, a change in the mean state owing to orbital forcing includes a change in both the annual mean and the amplitude of the seasonal cycle. Therefore, apart from the specific experiments in which we examine the effects of a change in the annual mean and seasonal cycle individually, when we refer to "a change in the mean state" it will always refer to changes to both the annual mean and seasonal cycle. We shall next use this system to incorporate output from two GCMs in order to diagnose what is responsible for the differences in the behavior of ENSO when these GCMs are forced with insolation from the modern day and from the early/midHolocene.

\section{ENSO in the modern day and early Holocene as seen from CSM}

In this section, we review the response of ENSO in CSM when the model is forced by modern-day and early Holocene insolation and then analyze the results using LOAM. We determine which of the mean field changes are most important for the changes in ENSO as simulated by CSM under modern-day and mid-Holocene forcing. We use a simulation of $8.5 \mathrm{ka}$ as this is closest to the minimum in ENSO activity shown by Tudhope et al. (2001) and Koutavas et al. (2006). For this reason, we use an 8.5-ka simulation rather than the Paleoclimate Modeling Intercomparison Project (PMIP) protocol's standard mid-Holocene simulation of $6 \mathrm{ka}$. The difference in insolation between $8.5 \mathrm{ka}$ and present day are much larger than that between the $8.5-\mathrm{ka}$ and $6-\mathrm{ka}$ simulations reported in Otto-Bliesner et al. (2003). Not surprisingly then, the difference between the mean states in the 8.5-ka simulation and the present-day CSM simulations are much greater than those between the 8.5-ka and 6-ka simulations. Hence, the results obtained below using LOAM for the 8.5-ka CSM simulation are also applicable to the 6-ka CSM simulation. We use 100 years of model output to construct the LOAM mean states, and over this period the model shows no noticeable trend in these quantities. We find that, when we construct LOAM on subsets of these 100 years, the differences between the different versions of LOAM are far smaller than the differences between LOAM constructed with mid-Holocene and modern-day mean states. Hence, the results that we present are ultimately brought about by changes in the insolation forcing and are not the result of unforced internal model variability.

\section{a. Modern-day and early Holocene mean states simulated by CSM}

The annual mean SST and surface winds from the CSM forced with present-day boundary conditions, denoted $\operatorname{CSM} p$, are shown in the top row of panels in Fig. 1 (although we note that in LOAM we use fields that vary 
(a)

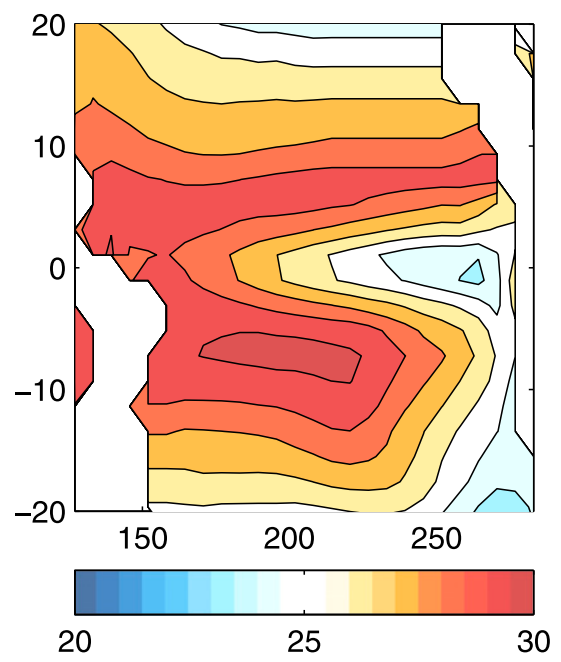

(b)

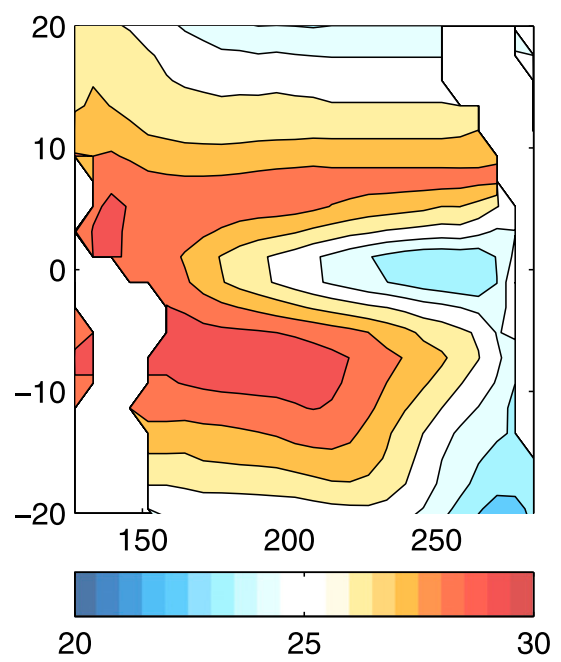

(c)

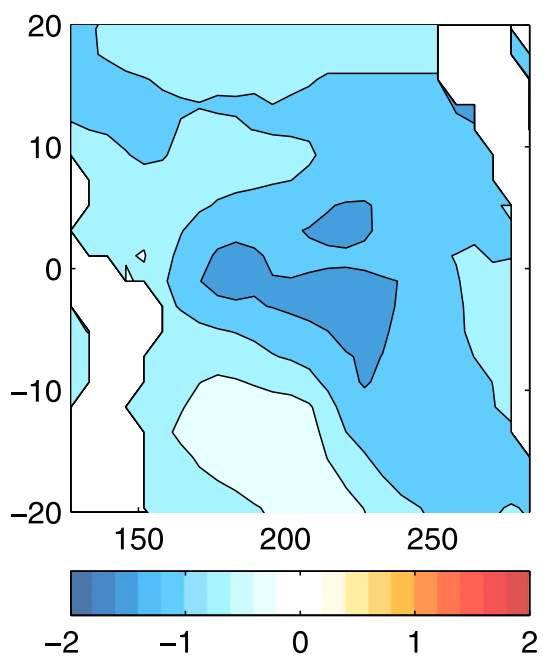

(d)

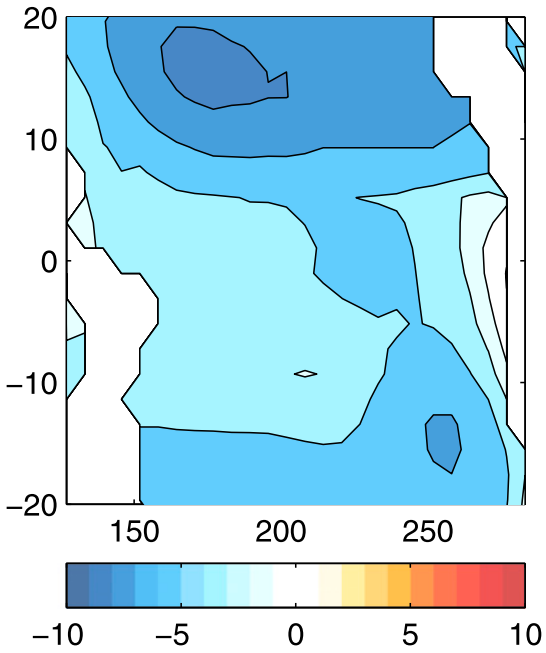

(e)

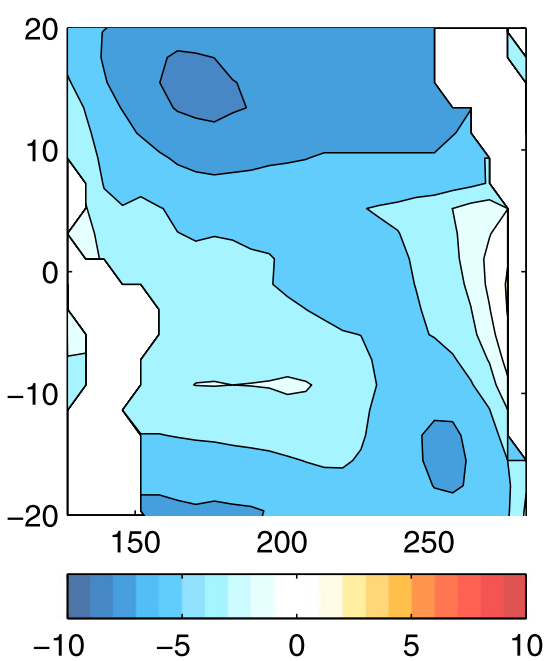

(f)

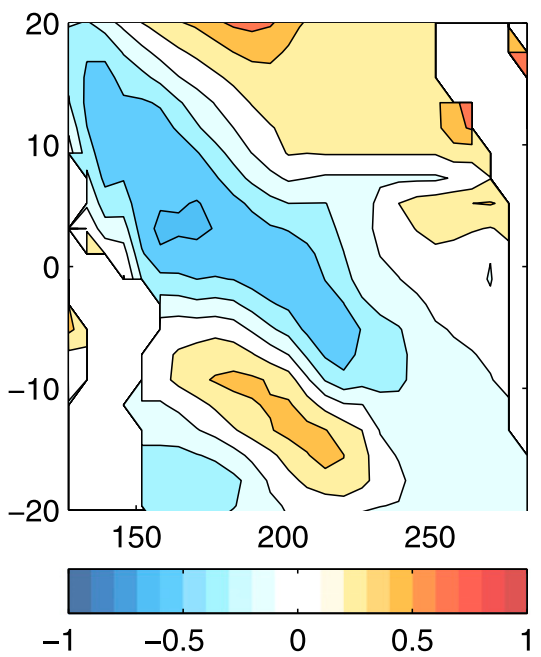

(g)

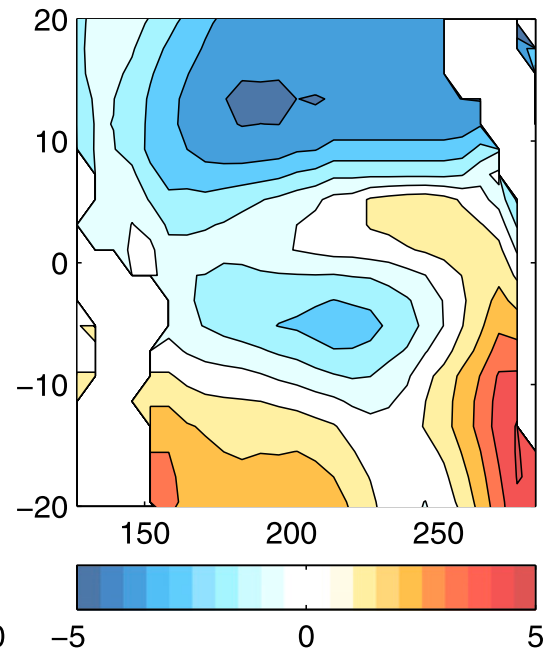

(h)

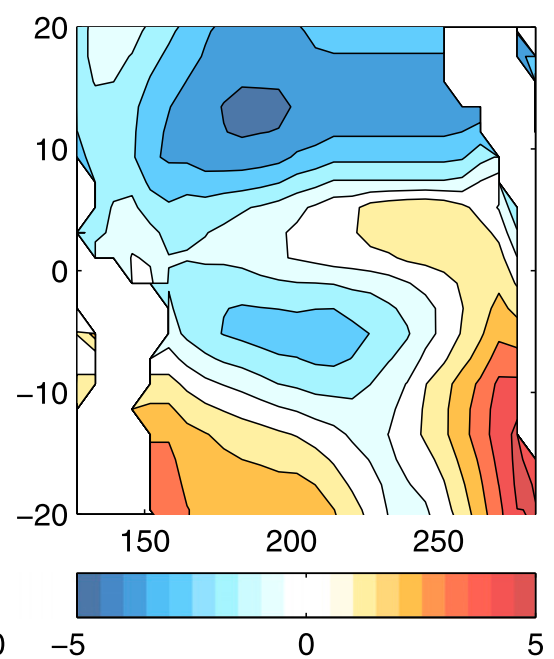

(i)

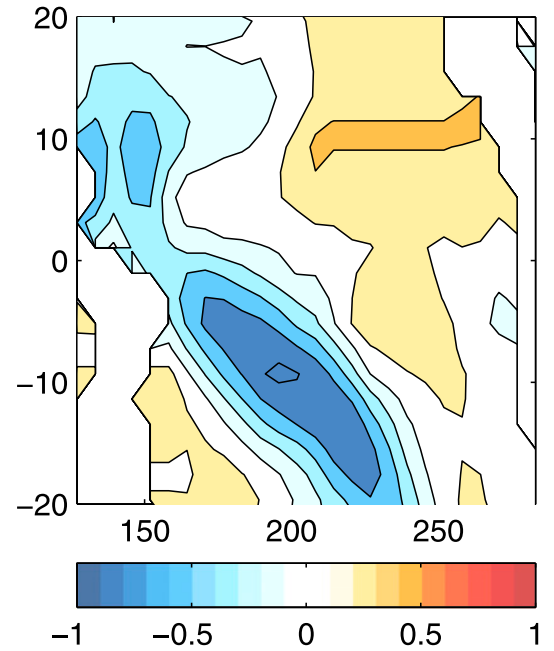

FIG. 1. Annual-mean SST from (a) CSM $p$ and (b) CSM 8.5 and (c) the difference. Annual-mean zonal wind from (d) CSM $p$, (e) CSM 8.5 , and (f) the difference. Annual-mean meridional wind from (g) $\operatorname{CSM} p$, (h) CSM 8.5 , and (i) the difference. The contour interval for SST is $1^{\circ} \mathrm{C}$ for climatology $\left(0.2^{\circ} \mathrm{C}\right.$ for differences); for wind it is $U: 2 \mathrm{~m} \mathrm{~s}^{-1}, V: 1 \mathrm{~m} \mathrm{~s}^{-1}$ for climatology $\left(0.4 \mathrm{~m} \mathrm{~s}^{-1}\right.$ for differences). 
over the annual cycle). These fields are broadly similar to those observed. Biases include a cold tongue that extends farther to the west than is observed and a warm pool south of the equator that extends too far to the east. The easterly trade winds on the equator are weaker, and the meridional winds are more southerly in the CSM than in the observations. As a consequence, upwelling along the equator is reduced in the model compared to that observed. A more complete discussion of the differences between CSM $p$ and the observed climate is found in Otto-Bliesner et al. (2003).

For the climate of the early Holocene we examine an integration of the CSM performed by Otto-Bliesner et al. (2003) that uses 8.5-ka insolation forcing, denoted CSM8.5. The mean SST and surface winds from this experiment are shown in Fig. 1, middle panels, and the differences, CSM8.5 minus CSM $p$, are shown in the bottom panels. The climatology of the early Holocene is broadly similar to that from the modern-day experiment, but the tropical Pacific is everywhere cooler by $\sim 1^{\circ} \mathrm{C}$ in the early Holocene compared to the modern-day simulation. This is because of an overall reduction in the radiative flux into the surface, especially near the ITCZ, and to larger evaporative cooling of the ocean owing to the stronger winds. The broad-scale pattern of the annual mean reduction in SST in the early Holocene of the tropics and subtropics is due to the reduction in annualaveraged insolation (Liu et al. 2003) associated with differences in obliquity. There is also an increase in the zonal SST gradient in the west-central Pacific at $8.5 \mathrm{ka}$ compared to the modern day that is due to local extrema of cooling in the central equatorial Pacific. This cooling is because of stronger trade winds in this region (shown in the middle column of panels in Fig. 1) and thus stronger equatorial upwelling. This cools the surface, further reducing SST in the central equatorial Pacific.

We recall from section $2 b$ that there are two parameterizations that affect how subsurface temperature affects SST: $T_{z}$ and $\Gamma$. The climatological vertical structure of temperature along the equator from the modern and early Holocene CSM is shown in Fig. 2. This structure is important for ocean wave dynamics and especially for the processes that determine anomalies in SST tendency that result from anomalies in the surface wind stress. We see in the bottom panel that along the equator, the ocean is cooler at all depths in the 8.5-ka run except within the thermocline west of about $160^{\circ} \mathrm{W}$. The vertical profile of temperature averaged over $2.5^{\circ} \mathrm{N}-2.5^{\circ} \mathrm{S}, 155^{\circ}-115^{\circ} \mathrm{W}$ for the modern and early Holocene simulations is shown in the right top and middle panels, respectively, and the difference is shown in the bottom right panel. This area is chosen because it coincides with the greatest change in upwelling. The depth of the $20^{\circ} \mathrm{C}$ isotherm, $h$, in the
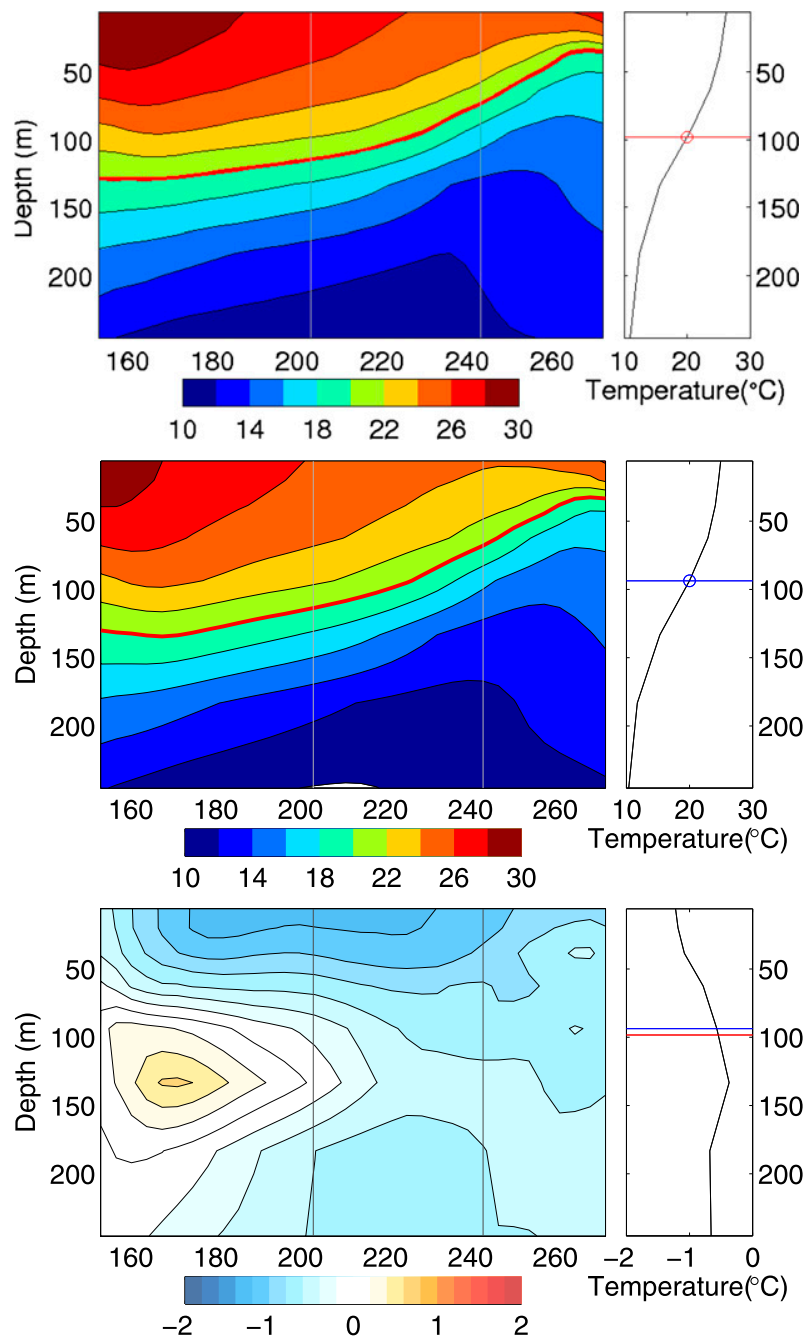

FIG. 2. Ocean temperature averaged over $2.5^{\circ} \mathrm{N}-2.5^{\circ} \mathrm{S}$. (left) Depth plotted against longitude. (right) Vertical profile of temperature averaged over $2.5^{\circ} \mathrm{N}-2.5^{\circ} \mathrm{S}, 155^{\circ}-115^{\circ} \mathrm{W}$ (the region indicated by the gray vertical lines in the left panels): (top) CSM $p$ and (middle) CSM8.5; (bottom) the difference, CSM8.5$\operatorname{CSM} p$ (contour interval $0.2^{\circ} \mathrm{C}$ ). Also shown in the right panels is the location of $20^{\circ} \mathrm{C}$ isotherm in the modern (red) and $8.5-\mathrm{ka}$ (blue) simulations.

early Holocene (blue line, $93.7 \mathrm{~m}$ ) is shallower than in the modern climate simulation (red line, $98.3 \mathrm{~m}$ ) by around $5 \mathrm{~m}$, which affects $\Gamma$. The vertical temperature gradient from the surface to about $130-\mathrm{m}$ depth is also weaker, which affects both $T_{z}$ and $\Gamma$.

\section{b. Modern-day and early Holocene ENSO simulated by $C S M$}

The first EOF of monthly averaged SST anomalies for the modern-day and early Holocene experiments using the CSM are shown in Fig. 3. The first EOF of CSM $p$ is similar to that from observations [similar figures for 

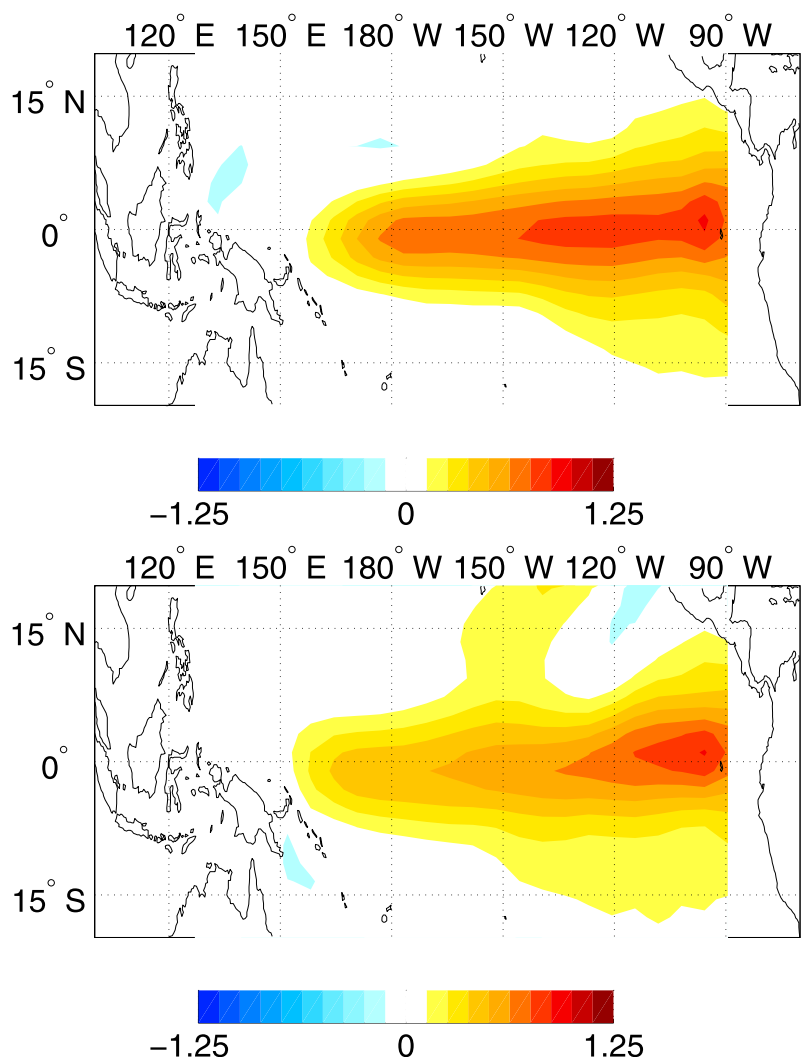

FIG. 3. EOF 1 of SST from the CSM: (top) the modern simulation $\mathrm{CSM} p$ and (bottom) the early Holocene simulations CSM8.5. Contours are in degrees Celsius for a unit normalized principle component. The EOF analysis is performed on monthly averaged model output and for the domain $30^{\circ} \mathrm{S}-30^{\circ} \mathrm{N}, 150^{\circ} \mathrm{E}-77^{\circ} \mathrm{W}$.

modern-day observations using LOAM can be found in Fig. 12 of Roberts and Battisti (2011)], but the EOF from the CSM is too constrained to the equator and extends too far to the west compared to the observed; both are common flaws of climate models. The variance in the CSM Niño-3 index, a standard measure of the amplitude of ENSO, is $0.52^{\circ} \mathrm{C}^{2}$, which compares well with that from the observations [e.g., $0.50^{\circ} \mathrm{C}^{2}$ in the Kaplan et al. (1998) dataset]. The probability distribution function of Niño-3 SST anomalies is shown in Fig. 4; the PDFs are not distinguishable from a Gaussian distribution at the $95 \%$ level using a Lilliefors test, which partly justifies the use of the linear framework of LOAM to analyze the CSM ENSO. The first EOF of monthly SST for the early Holocene experiment is shown in Fig. 3b; it is similar to that from the modern-day experiment, although the maximum in the pattern is shifted farther to the east compared to the modern-day experiment (cf. Figs. 3a and 3b). The second and third EOFs of SST are not well separated [in the sense of North et al. (1982)] and so are not discussed.

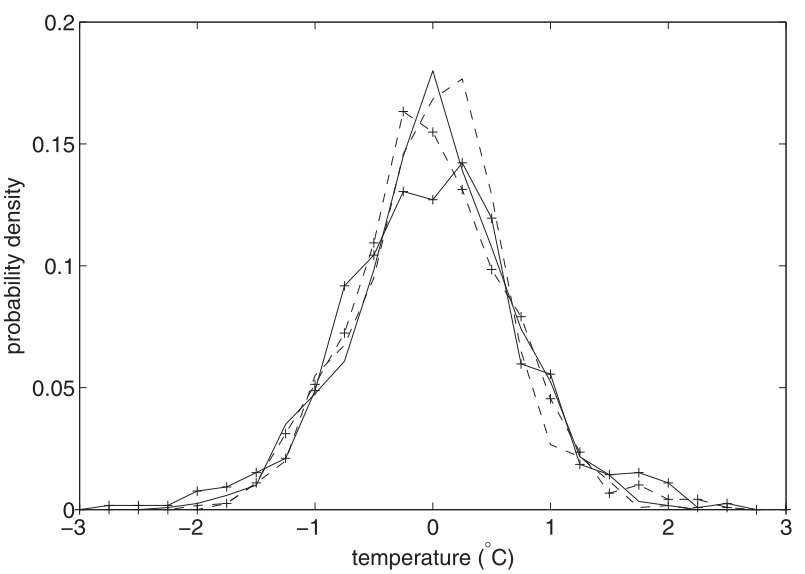

FIG. 4. Probability density function of the Niño-3 SST anomalies. The anomalies are standardized to a unit standard deviation. Solid line with crosses is HadCM $p$; dashed lines with crosses is HadCM6; unadorned solid is CCSMp; and unadorned dashed is CCSM8.5. All series are indistinguishable from a Gaussian distribution at the 95\% level using a Lilliefors test.

Table 2 shows that the variance of the Niño-3 index from CSM is reduced by $19 \%$ at $8.5 \mathrm{ka}$ to $0.42^{\circ} \mathrm{C}^{2}$. This reduction is statistically significant (at the $95 \%$ level using an $F$ test). [We note that this reduction is somewhat different from that quoted in the original study (and cited in Table 1) because we do not use the exact same time interval as Otto-Bliesner et al. (2003); the difference in estimated variance is consistent with the natural, unforced variability in the model ENSO.] The cause of the reduction of variance and the eastward shift in the EOF will be made clear in section 3d.

\section{c. Analysis of ENSO in the CSM using LOAM}

In this section, we insert the modern-day and early Holocene mean fields from the CSM, CSM $p$, and CSM8.5 into LOAM. These experiments are called LOAM $p$ and LOAM8.5, respectively. We then force LOAM $p$ and LOAM8.5 with white noise and compare the temporal and spatial statistics from LOAM to those from the CSM. We force LOAM forward in time with a stochastic forcing on the SST field that is white in time and normally distributed in space about the equator [see Thompson and Battisti (2001) and Penland and Sardeshmukh (1995) for further discussion]. The amplitude of this noise is chosen so that, when the modern-day climatology from the CSM is inserted in LOAM ( $\operatorname{LOAM} p)$, the variance of Niño-3 is identical to that in CSM $p$. This same amplitude of noise is used in all subsequent runs of LOAM. Hence, any change in the period, decay rate, structure, and variance of ENSO is only due to the changes in the mean state. We will first show results from the output of the stochastically forced LOAM that contain all of the mean state fields taken from CSM $p$ and CSM8.5. 
TABLE 2. ENSO statistics from the CSM early Holocene (CSM8.5) and modern (CSMp) simulations and from LOAM using the seasonally varying mean state fields from the two aforementioned CSM simulations (LOAM8.5 and LOAM $p$ ). The top rows show ENSO statistics from the modern CSM (CSM $p)$ and 8.5-ka (CSM8.5) simulations and from LOAM using the mean state fields from the two aforementioned CSM simulations (LOAM $p$ and LOAM8.5). Subsequent rows are from LOAM using a mixture of early Holocene and modern mean states. The second column shows the Niño-3 variance, standardized by the Niño-3 variance in the relevant modern-day experiment (modern CSM or LOAM with modern CSM mean fields). The third and fourth columns show the period and decay rate of the ENSO mode. The decay rate is the change in amplitude of the ENSO mode over one full year. The ENSO mode for LOAM is derived from the Floquet analysis of LOAM.

\begin{tabular}{lccc}
\hline \hline \multicolumn{1}{c}{ Model } & $\begin{array}{c}\text { Variance/ } \\
\text { (modern-day } \\
\text { variance) }\end{array}$ & $\begin{array}{c}\text { Mode } \\
\text { period }(\mathrm{yr})\end{array}$ & $\begin{array}{c}\text { Mode } \\
\text { decay }\left(\mathrm{yr}^{-1}\right)\end{array}$ \\
\hline CSM $p$ & 1.00 & & \\
CSM8.5 & 0.81 & & \\
LOAM $p$ & 1.00 & 2.15 & 0.70 \\
LOAM8.5 & 0.79 & 2.92 & 0.74 \\
LOAM $p+$ ocn & 1.35 & 2.87 & 0.81 \\
LOAM $p+\Gamma+\overline{T_{z}}$ & 2.42 & 2.94 & 0.92 \\
LOAM $p+T_{z}$ & 0.87 & 2.20 & 0.69 \\
LOAM $p+\Gamma$ & 2.83 & 2.89 & 0.93 \\
LOAM $p+$ curr & 1.38 & 2.00 & 0.67 \\
LOAM $p+$ atm & 0.51 & 2.27 & 0.63 \\
LOAM $p+T_{\text {atm }}$ & 0.49 & 2.30 & 0.62 \\
LOAM $p+\tau_{\text {atm }}$ & 1.12 & 2.11 & 0.71 \\
LOAM $p+$ cyc $\left(T_{\text {atm }}\right)$ & 1.06 & 2.13 & 0.70 \\
LOAM $p+$ mean $\left(T_{\text {atm }}\right)$ & 0.47 & 2.31 & 0.61 \\
LOAM $8.5+\Gamma$ & 0.57 & 2.00 & 0.59 \\
LOAM8.5 $+T_{\text {atm }}$ & 1.53 & 2.80 & 0.84 \\
\hline
\end{tabular}

Figure 5 shows the EOFs that result from the LOAM $p$ and LOAM8.5 experiments. The first EOF of each LOAM run compares well with its CSM counterpart (cf. Figs. 3 and 5). The first EOF of SST from the modern-day LOAM simulation features a maximum in the eastern half of the Pacific basin and is narrowly confined to the equator. As in the CSM8.5 experiments, the first EOF of SST from the early Holocene simulation of LOAM is weighted eastward of that from the modern simulation. We see, in Table 2, that the variance in Niño-3 of the LOAM8.5 experiment is 0.79 times that of the LOAM $p$ experiment, in good agreement with the reduction in Niño-3 variance in CSM8.5 compared to CSM $p$. Since there is no change in the amplitude or structure of the noise forcing in the two LOAM experiments, the reduction in the variance and the differences in the first EOF are solely due to the changes in the mean state.

Also shown in Table 2 are the period and decay rate of the dominant Floquet mode that result from LOAM
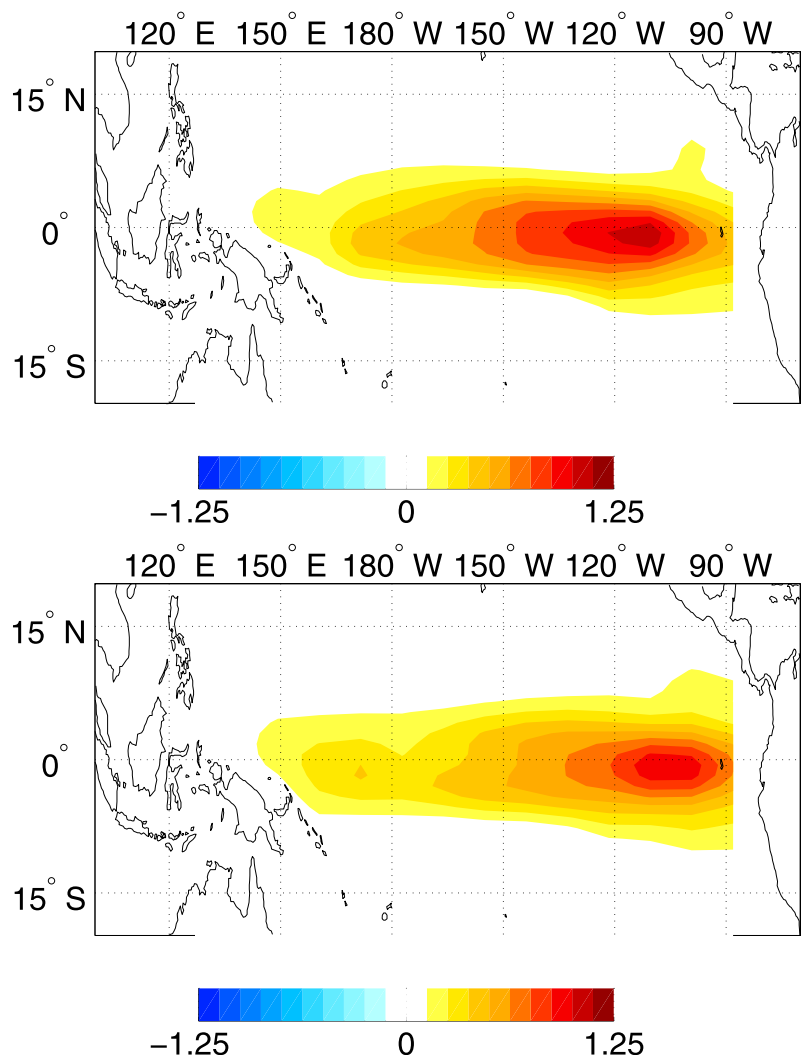

FIG. 5. EOF 1 of SST from LOAM using the mean fields from the CSM modern and early Holocene simulations: (top) the modern simulation LOAM $p$ and (bottom) the early Holocene simulations LOAM8.5. Contours are in degrees Celsius for a unit normalized principle component.

(hereafter referred to as the dynamical ENSO mode). The decay rate of the dynamical ENSO mode, which is defined as the change in the amplitude of the ENSO mode over one full year, in the early Holocene is similar to that in the modern climate; however, the period of the ENSO mode is greater in the 8.5-ka case compared to the modern day. The longer period of the ENSO mode in the early Holocene is consistent with an eastward shift in the centroid of the zonal wind stress (not shown) acting in the Bjerknes feedback processes in the dynamical ENSO mode (see Battisti 1988). This increases the time it takes for waves to transit from the center of action for the atmosphere-ocean (Bjerknes) feedbacks, in the central eastern Pacific, to the western boundary and back and enhances the period of ENSO (Battisti and Hirst 1989). This is also reflected in the shift to the east of the peak SST anomalies in the first EOF of SST discussed above. Other metrics also demonstrate this lengthening of the ENSO mode period (Roberts 2007).

The ability of LOAM to simulate the temporal and spatial characteristics of the interannual variability in 
CSM $p$ allows us to proceed using LOAM to determine which changes in the mean state fields and which processes account for the differences in the ENSO in the modern and early Holocene CSM simulations.

\section{d. Diagnosis of the important mean state changes using LOAM}

To diagnose the impact of the mean state changes on the ENSO in the CSM, in this section we start from the modern-day mean fields from CSM $p$ used in LOAM $p$ and swap out selected mean states, $x$, and replace them with those that come from the early Holocene CSM experiment CSM8.5. This gives a new LOAM called LOAM $p+x$. We then force the modified LOAM with the identical forcing to LOAM $p$ (and LOAM8.5) to examine the impact of the change in mean state variable $x$. Although the modified climatology is not physically selfconsistent, the changes in the leading Floquet mode and in the statistical properties for the stochastically forced LOAM will illuminate which mean state changes are important for the changes in ENSO variability in the CSM experiments. We first swap out ocean mean state variables and then change the atmospheric mean states. Results for all of the experiments are summarized in Table 2.

\section{1) OCEAN MEANS}

The first experiment, LOAM $p+$ ocn, replaces all ocean mean states of LOAM $p$ with those from LOAM8.5. These ocean mean states are the ocean currents, SST, the wind speed used to calculate the wind stress on the ocean, and the subsurface parameterizations $\Gamma, \overline{T_{z}}$. Note that the wind speed and SST that the atmosphere model sees remain the same as for LOAM $p$. The period of the ENSO mode increases from $2.15 \mathrm{yr}$ in LOAM $p$ to $2.87 \mathrm{yr}$ in LOAM $p+$ ocn, and the ENSO mode becomes less stable: the decay rate decreases from 0.70 to $0.81 \mathrm{yr}^{-1}$. The variance of Niño-3 from the stochastic run of LOAM $p+$ ocn increases by a factor of 1.35 compared to that from LOAM $p$. Hence, changes in the ocean mean state appear to account for the lengthening of the period of the ENSO mode in the early Holocene but would have caused an increase in ENSO variance in the early Holocene. Since this increase in variance of ENSO is not observed in LOAM8.5, there must be some compensating mechanism elsewhere that increases the stability of the ENSO mode.

To isolate the impact of changes in the mean vertical structure of the ocean, we insert only the values of the subsurface parameterization $\Gamma$ and $\overline{T_{z}}$ from the CSM8.5 experiment into LOAM $p$ and create the new LOAM model LOAM $p+\Gamma+\overline{T_{z}}$. Changes in the vertical structure of the ocean increase the period of the ENSO mode from 2.15 to $2.94 \mathrm{yr}$ and render the ENSO mode less stable: the decay rate decreases from 0.70 to $0.92 \mathrm{yr}^{-1}$. The stochastically forced LOAM $p+\Gamma+\overline{T_{z}}$ greatly increases the variance of Niño-3 by a factor of 2.42 . Further experiments in which we change $\Gamma(\operatorname{LOAM} p+\Gamma)$ and $\overline{T_{z}}\left(\mathrm{LOAM} p+\overline{T_{z}}\right)$ separately suggest that the increase in the period of the ENSO mode is due to the change in $\Gamma$ (see Table 2). We recall from section $3 a$ and Fig. 2 that the thermocline was shallower in CSM8.5 than in $\operatorname{CSM} p$. With the thermocline closer to the surface at $8.5 \mathrm{ka}$, movements in the thermocline cause greater temperature anomalies at $50 \mathrm{~m}$; this is reflected in LOAM by changes in $\Gamma$. The result is that the ENSO mode is less stable in LOAM8.5 than in LOAM $p$. The spatial pattern of the ENSO mode and the first EOF of SST in $\operatorname{LOAM}_{p}+\Gamma$ also show an eastward shift in the peak SST. This is the result of the maximum value of $\Gamma$ being shifted farther to the east at 8.5 ka relative the modern. This eastward shift in the pattern is consistent with an increase in the period of the ENSO mode, as discussed in Battisti and Hirst (1989).

Replacing only the mean-state ocean currents (including upwelling) with those from the early Holocene (LOAM $p+$ curr) shows that changes in the mean-state ocean currents do not greatly affect the decay rate or period of the mode, but in the absence of other mean state changes they would have enhanced the variance of ENSO (see Table 2).

The conclusion that can be drawn from this series of experiments is that in the CSM simulations, changes in the mean state of the ocean in the early Holocene render the ENSO mode less stable and increase its period with the result that the variance of Niño-3 increases. Of particular importance are changes in the subsurface parameterization that govern the temperature of the water entrained into the surface layer as a result of changes in the depth of the thermocline. Changes in these subsurface parameterizations alone can account for the increase in the period of the ENSO mode in the early Holocene seen in LOAM and the CSM. In isolation, however, this mean-state ocean change would have also rendered a less stable ENSO mode giving an increase in the variance of ENSO, which is not consistent with the change seen between CSM $p /$ LOAM $p$ and CSM8.5/LOAM8.5.

\section{2) ATMOSPHERIC MEANS}

Next, we replace the mean states in $\operatorname{LOAM} p$ that affect the atmospheric response-SST and wind speedwith their 8.5-ka counterparts; this experiment is called $\mathrm{LOAM} p+$ atm (note that in this experiment the mean state SST and wind speed seen by the ocean are not the same as those seen by the atmosphere). This results in a more stable ENSO mode, as shown in Table 2. When 
$\operatorname{LOAM} p+\operatorname{atm}$ is run with stochastic forcing, the variance of Niño-3 is cut by nearly half compared to LOAM $p$. Since the changes in the ocean mean fields act to increase the variance of ENSO, the reduction in variance in the early Holocene in LOAM8.5 (and therefore most likely in CSM8.5) is due to the changes in the mean state quantities and processes that intrinsically affect the atmosphere.

The mean states in the atmosphere determine the amount of latent heating the atmosphere experiences from a unit sea surface temperature anomaly as well as the wind stress anomaly that results from a unit change in wind stress. The latent heating of the atmosphere is affected by the mean state SST through the dependence of evaporation on SST (assuming a constant relative humidity and air-sea temperature difference) and by the climatological low-level winds through feedbacks associated with the climatological low-level moisture convergence (see Zebiak 1986).

We isolate the impact of the changing mean state SST on the response of the atmosphere by creating LOAM $p+T_{\text {atm }}$ in which the modern mean state SST that the atmosphere sees is replaced by the early Holocene mean state SST from the CSM8.5 experiment; all other mean state fields are from the modern-day CSM experiment. Compared to LOAM $p$, the period of the ENSO mode in LOAM $p+T_{\text {atm }}$ is not changed significantly from that in $\operatorname{LOAM} p$, but the decay rate of the ENSO mode is increased from 0.70 to $0.62 \mathrm{yr}^{-1}$, and the variance of the Niño-3 index in the stochastically forced LOAM $p+T_{\text {atm }}$ is reduced by more than half (0.49) compared to that in LOAM $p$. Replacing the low-level winds in LOAM $p$ with those from the early Holocene $\mathrm{CSM} p$ simulation, LOAM $p+\tau_{\mathrm{atm}}$, gives an ENSO mode that is very similar to that in $\operatorname{LOAM} p$ and, when stochastically forced, gives a slight increase in the Niño-3. Hence, to the extent that LOAM faithfully represents the essential physics of the tropical Pacific ENSO variability in the CSM, ENSO is reduced in the early Holocene because the tropical Pacific Ocean is cooler, and thus the response of the atmosphere to a unit SST anomaly is weaker.

Roberts (2007) performed pairs of experiments using the atmospheric component of the LOAM to confirm that the overall cooling of the tropical Pacific in the early Holocene reduces the amplitude of the anomalous wind stress response to a canonical El Niño SST anomaly compared to that in the (warmer) modern-day climate. Together with the coupled LOAM analysis, these results confirm the expectation that a $1^{\circ} \mathrm{C}$ change in the SST will lead to approximately a $6 \%$ reduction in the saturated vapor pressure, which would lead to a similar sized reduction in the climatological low-level moisture convergence. In effect, the cooler mean state SST stabilizes the ENSO mode by reducing the coupling strength between the atmosphere and the ocean in the equatorial band in the central and eastern Pacific, that is, by reducing the strength of the Bjerknes feedback.

\section{3) SEAsonality}

We have demonstrated that ENSO variance is reduced in the early Holocene in the CSM because of changes in the mean state SST. In LOAM the mean states vary over the annual cycle; thus, there are two constituent parts of the mean state that change between the modern day and early Holocene: the annual mean and the amplitude/phasing of the seasonal cycle. To determine the relative importance of changes in the annual average SST and changes in the annual cycle of SST, we perform two additional experiments LOAM $p+$ $\operatorname{mean}\left(T_{\mathrm{atm}}\right)$ and LOAM $p+\operatorname{cyc}\left(T_{\mathrm{atm}}\right) \cdot \operatorname{LOAM} p+$ mean $\left(T_{\mathrm{atm}}\right)$ uses CSM $p$ mean states for all fields except the SST that the atmosphere sees. This SST is derived by calculating the annual cycle of the SST from CSM $p$ and adding to this the change in the annual mean SST of CSM8.5; thus, the annual cycle in this experiment is the same as in $\operatorname{CSM} p$, but the annual mean SST is as in CSM8.5. LOAM $p+\operatorname{cyc}\left(T_{\mathrm{atm}}\right)$ is a similar experiment, but in this case the annual cycle comes from CSM8.5 and the annual mean SST from CSM $p$.

We see, in Table 2, that changing the annual cycle of SST to that from $8.5 \mathrm{ka}$ does not reduce the variance of Niño-3; rather the change increases it, although this change in the variance is very small. On the other hand, LOAM $p+\operatorname{mean}\left(T_{\text {atm }}\right)$ shows a reduction in the variance of Niño-3 of 0.47 and an increase in the decay rate of the ENSO mode from 0.7 to $0.61 \mathrm{yr}^{-1}$. This shows that it is the annual mean cooling of the tropical Pacific SST that causes the increases in the stability of the ENSO mode: the change in the seasonality is unimportant. This agrees with Wang and An (2002) who noted that, when considering the climate shift in the 1970s, seasonal cycle changes are not nearly as important as changes in the annually averaged mean in altering the properties of ENSO.

\section{4) Some FinAl tests}

To demonstrate that the changes in $\Gamma$ in the ocean and the SST in the atmosphere are the most important mean states changes for explaining the changes in the ENSO mode and the spatiotemporal structures of variance in the CSM, we ran two further experiments. These replace mean states in LOAM8.5 with those from the modern day. The first experiment, called LOAM8.5 $+\Gamma$, uses all of the LOAM8.5 mean state changes except for $\Gamma$, which is from LOAM $p$. Since $\Gamma$ from LOAM8.5 had a destabilizing effect on the ENSO mode in LOAM $p$, we should 
expect that $\Gamma$ from LOAM $p$ will stabilize the ENSO mode in LOAM8.5. Table 2 shows that this is indeed the case: the ENSO mode decay rate goes from 0.74 in LOAM8.5 to 0.59 in LOAM8.5 + $\Gamma$. Note also that the period of the ENSO mode period drops from 2.92 to $2.00 \mathrm{yr}$, which further confirms the importance of $\Gamma$ in changing the period of the ENSO mode. In the second experiment, called LOAM8.5 $+T_{\text {atm }}$, we insert the mean state SST from CSM $p$ into LOAM8.5. As expected, the ENSO mode is less stable in LOAM8.5 + $T_{\text {atm }}$ compared to that in LOAM8.5 (the decay rate is $0.84 \mathrm{yr}^{-1}$ in LOAM8.5 $+T_{\text {atm }}$ and $0.74 \mathrm{yr}^{-1}$ in LOAM8.5). Hence, the change in the variance of Niño-3 is in the sense that we expect in both sets of experiments: compared with LOAM8.5, the variance decreases in LOAM8.5 $+\Gamma$ and increases in LOAM8.5 $+T_{\text {atm }}$.

\section{ENSO in the modern day and mid-Holocene as seen from HadCM3}

This section follows the same structure as section 3, only here we illuminate the cause of the differences in ENSO in the simulations of the preindustrial and midHolocene (6 ka) climate using HadCM3 (with no flux corrections) that were reported by Brown et al. (2008). We call these two GCM simulations HadCM $p$ and HadCM6, respectively. We use the 6-ka simulation because an 8.5-ka simulation using the HadCM3 is not available. However, as previously noted, the differences between either 8.5 or $6 \mathrm{ka}$ and the modern-day insolation are much greater than between 8.5 -ka and 6-ka insolation. Hence, we consider the difference between the 6-ka and modern-day HadCM3 experiments comparable to the difference between the 8.5-ka and modern-day CSM experiments. We use 100 years of model output to construct the LOAM mean states; over this period the model shows no noticeable trend in these quantities.

\section{a. Modern-day and mid-Holocene mean states simulated by HadCM3}

The HadCM3 modern-day simulation $\operatorname{HadCM} p$ features a tropical Pacific climate that is in reasonable agreement with the observations (see, e.g., Fig. 6, top row). Among the notable differences between $\operatorname{HadCM} p$ and observed climate are a simulated cold tongue that extends too far to the west and easterly trade winds that are stronger than those observed. Ocean currents in $\operatorname{HadCM} p$ are shown in Fig. 7; they are similar to those observed but are generally too strong.

The tropical Pacific climate from the mid-Holocene HadCM3 simulation (HadCM6) is shown in the middle row of Fig. 6 . The trade winds are slightly stronger at
$6 \mathrm{ka}$ compared to the modern simulation, especially in the central Pacific, while ocean currents are broadly similar in the 6-ka and modern simulations. Although modest compared with the CSM simulations, the tropical Pacific SST at $6 \mathrm{ka}$ is everywhere slightly cooler than in the modern climate. As is shown in Fig. 8, ocean cooling is confined to the near surface; water in and below the thermocline is warmer in the mid-Holocene than in the modern climate. The mean depth of the thermocline changes little, from 126 to $123 \mathrm{~m}$. Cooling near the surface and warming below weakens the vertical temperature gradient (Fig. 8, right); this turns out to be important for understanding the changes in ENSO in HadCM3, as we now demonstrate.

\section{b. Modern-day and mid-Holocene ENSO simulated by HadCM3}

The modern HadCM3 simulation features ENSO-like variability with spatial and temporal characteristics that are in good agreement with those observed (Collins et al. 2001). The variance in the Niño-3 index in HadCM $p$ is $0.68^{\circ} \mathrm{C}^{2}$, and the first EOF of SST is very similar to that observed (not shown). The PDFs of the normalized Niño-3 SST anomalies from the HadCM $p$ and from the mid-Holocene simulation HadCM6 are shown in Fig. 4 and are statistically indistinguishable from a Gaussian at 95\% (using a Lilliefors test). This partially justifies our use of the linear framework in LOAM. Spatially, there is very little difference between the SST anomalies in HadCM $p$ and HadCM6. For example, the first EOF of SST in both runs is nearly identical (not shown).

The variance of ENSO at $6 \mathrm{ka}$ is reduced by $18 \%$ in the mid-Holocene compared to the modern simulation. Although this is a statistically significant difference at the $95 \%$ level using an $F$ test, it has been noted that the amplitude of ENSO varies considerably on long time scales in HadCM3. In a 1000-yr run of HadCM3 using modern-day forcing, centuries with ENSO amplitude as low as that in the 6-ka run can be found (Collins 2000). Therefore, it is possible that the reduced ENSO activity at $6 \mathrm{ka}$ is not the result of the external forcing but the result of internal variability within the model. This internal model variability is also responsible for the slightly smaller ENSO variance reduction that we report compared to Brown et al. (2008).

\section{c. Analysis of ENSO in HadCM3 using LOAM}

We now use LOAM to examine the spatiotemporal variability in the two HadCM3 simulations. As in section $3 \mathrm{c}$, we create different versions of LOAM by inserting the modern and 6-ka mean fields from HadCM3 into LOAM; we call these two models LOAM $p_{h}$ and LOAM6 ${ }_{h}$, respectively. We perform the uncoupled tuning of an 
(a)

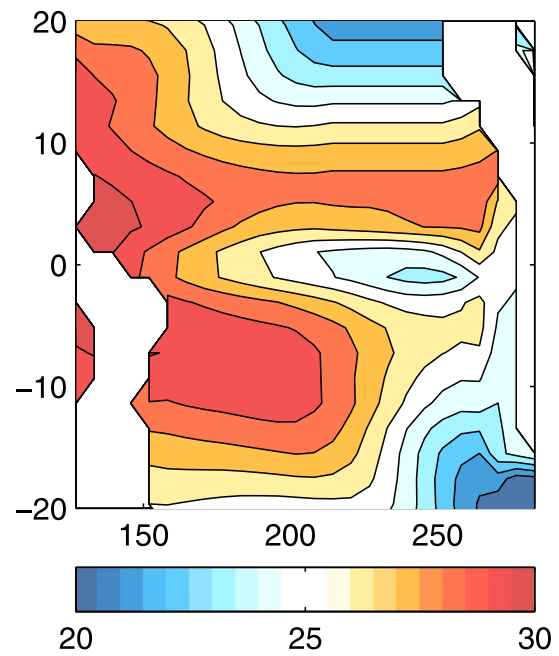

(b)

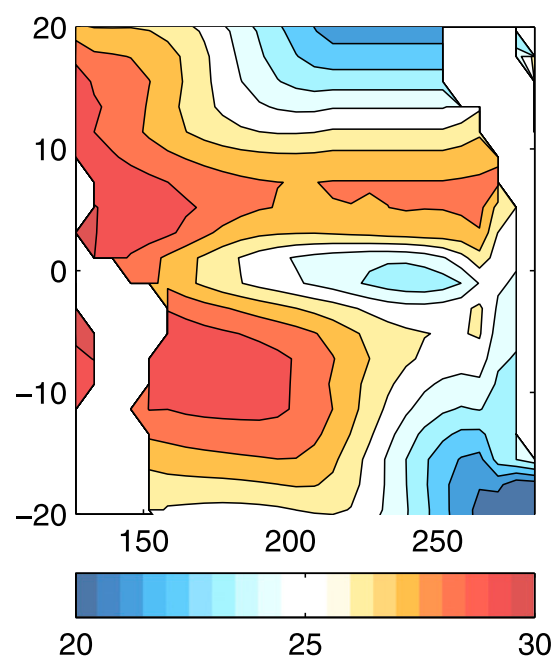

(c)

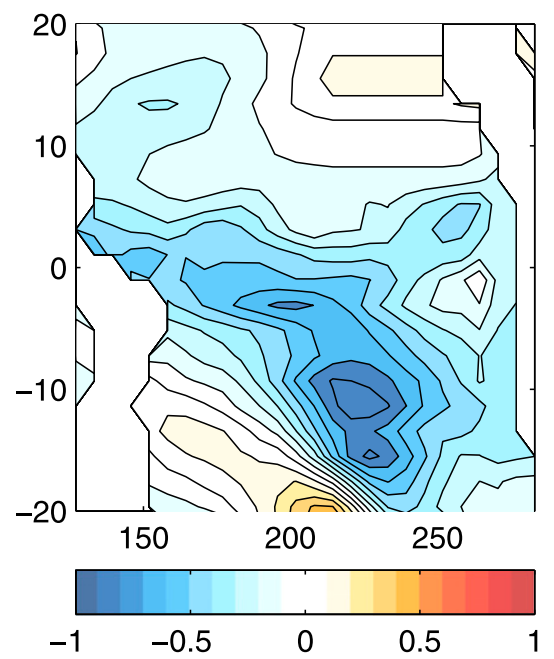

(d)

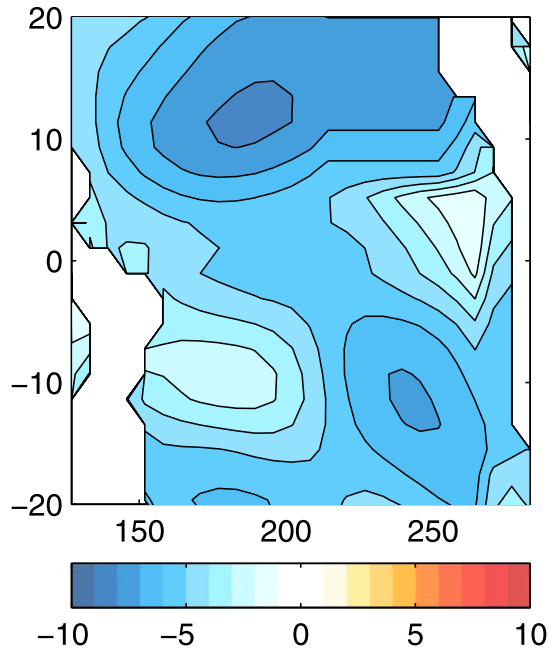

(e)

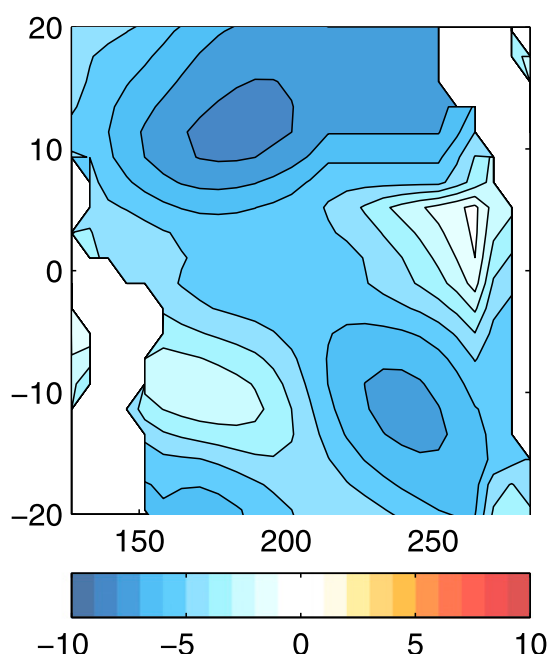

(f)

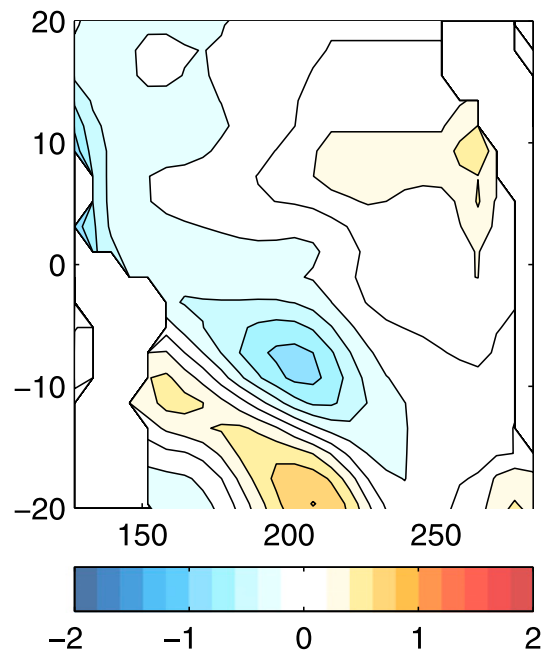

(g)

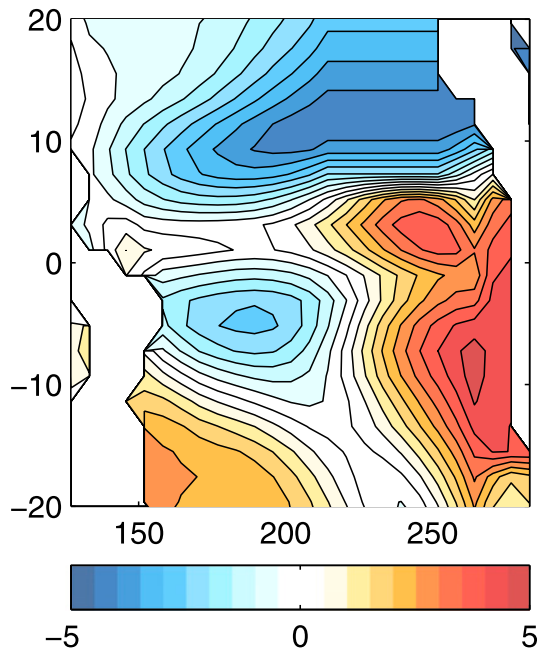

(h)

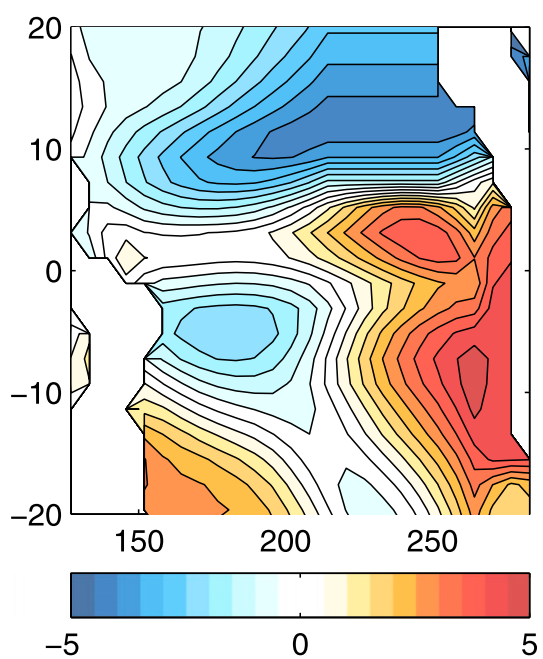

(i)

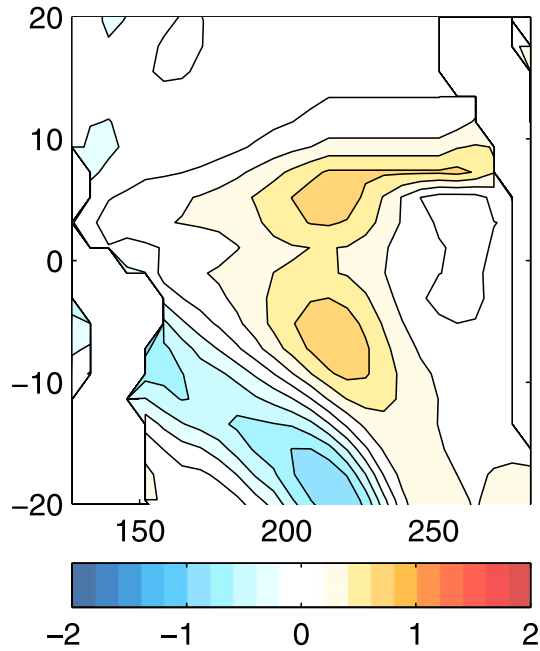

FIG. 6. Annual-mean SST from (a) $\operatorname{HadCM} p$, (b) HadCM6, and (c) the difference. Annual-mean zonal wind from (d) $\operatorname{HadCM} p$, (e) HadCM6, and (f) the difference. Annual-mean meridional wind from (g) HadCMp, (h) HadCM6, and (i) the difference. Contour interval as in Fig. 1. 
(a)

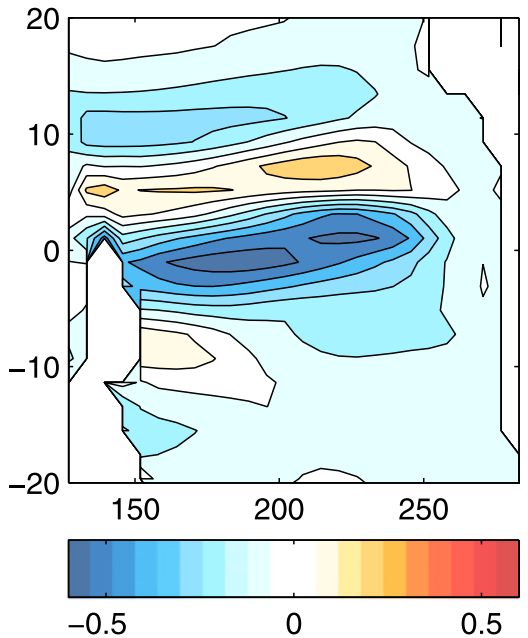

(b)

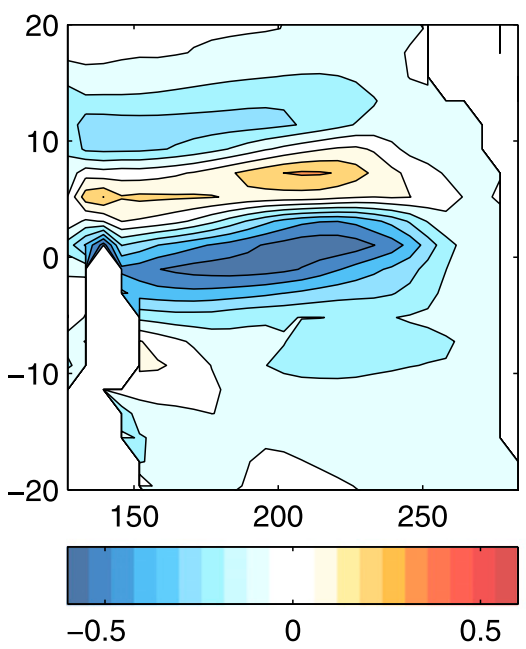

(c)

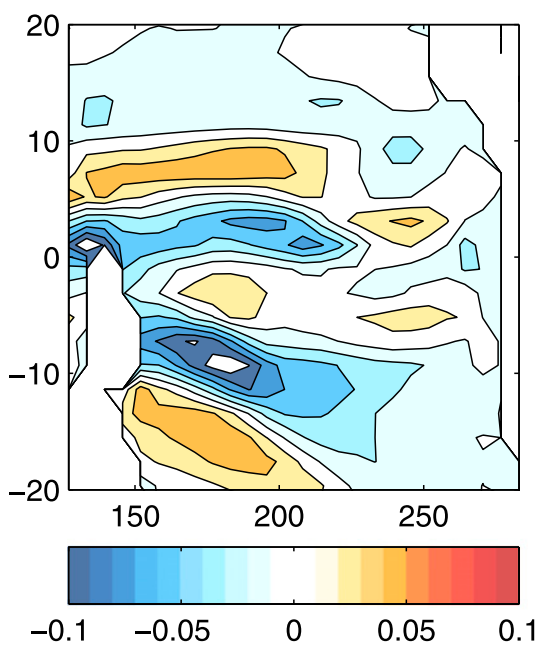

(d)

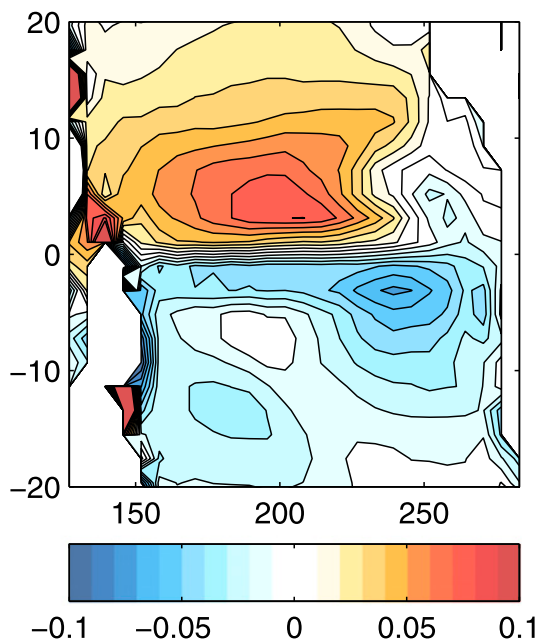

(e)

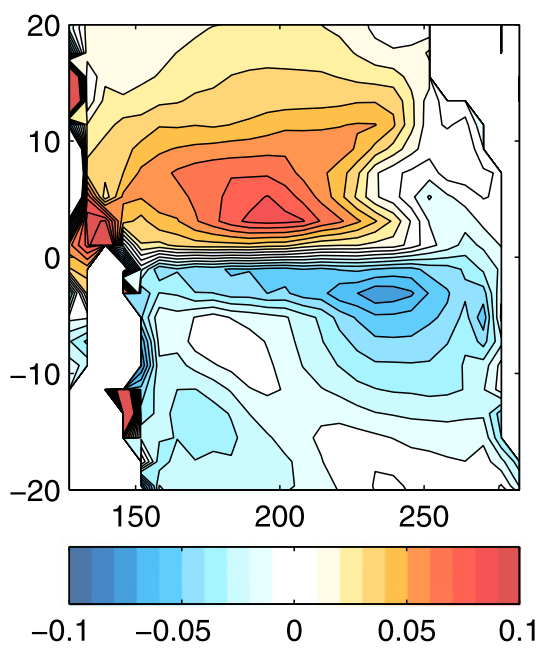

(f)

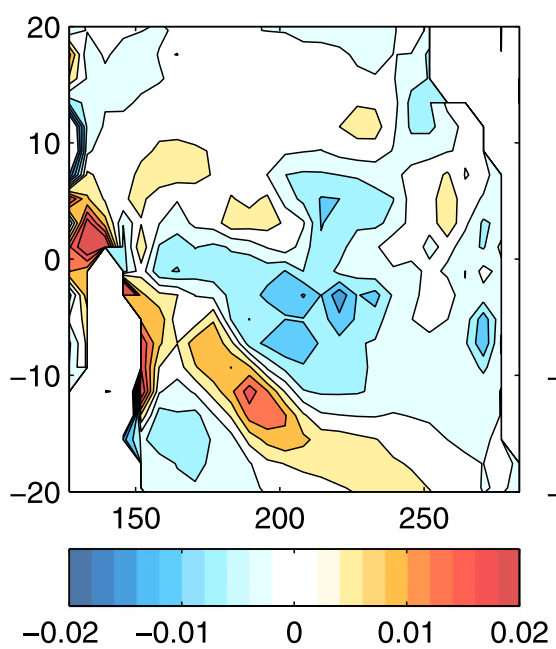

(g)

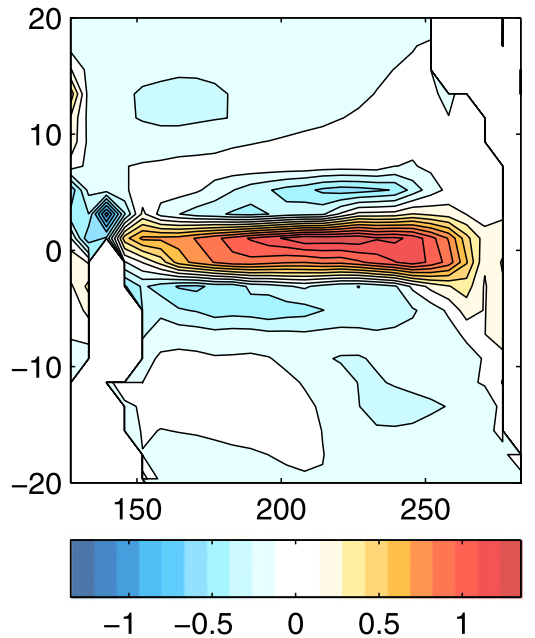

(h)

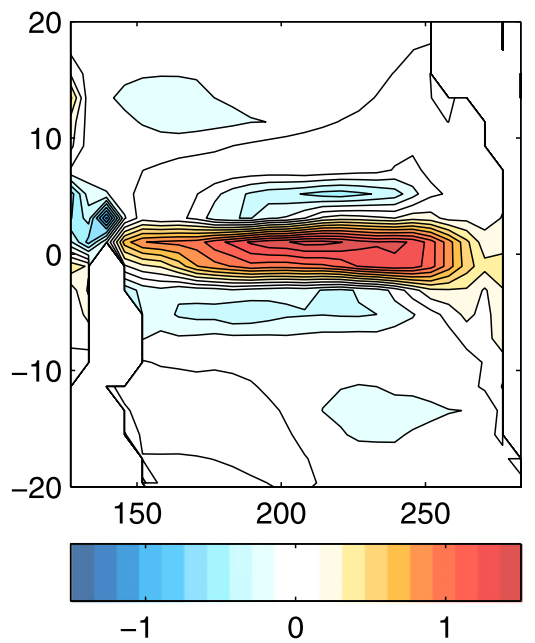

(i)

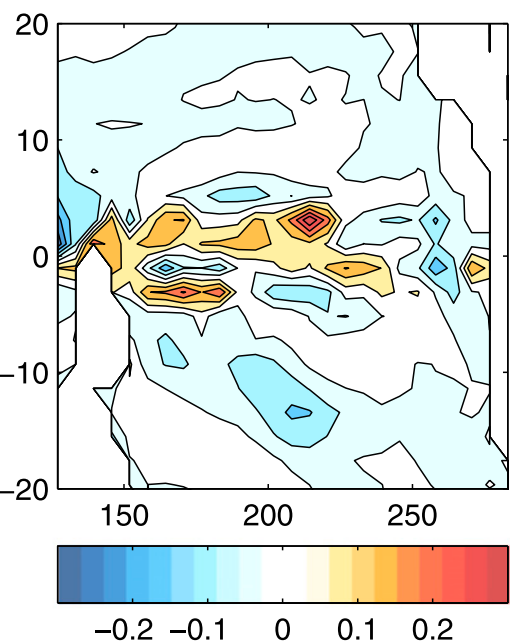

FIG. 7. Annual-mean zonal currents from (a) HadCMp, (b) HadCM6, and (c) the difference. Annual-mean meridional currents from (d) HadCMp , (e) HadCM6, and (f) the difference. Annual-mean upwelling from (g) HadCM $p$, (h) HadCM6, and (i) the difference. The contour interval for zonal currents is $0.1 \mathrm{~m} \mathrm{~s}^{-1}$ for climatology $\left(0.02 \mathrm{~m} \mathrm{~s}^{-1}\right.$ for differences), for meridional currents is $0.02 \mathrm{~m} \mathrm{~s}^{-1}$ for climatology ( $0.004 \mathrm{~m} \mathrm{~s}^{-1}$ for differences), and for vertical velocity it is $0.25 \mathrm{~m} \mathrm{day}^{-1}$ for climatology $\left(0.05 \mathrm{~m} \mathrm{day}^{-1}\right.$ for differences). 

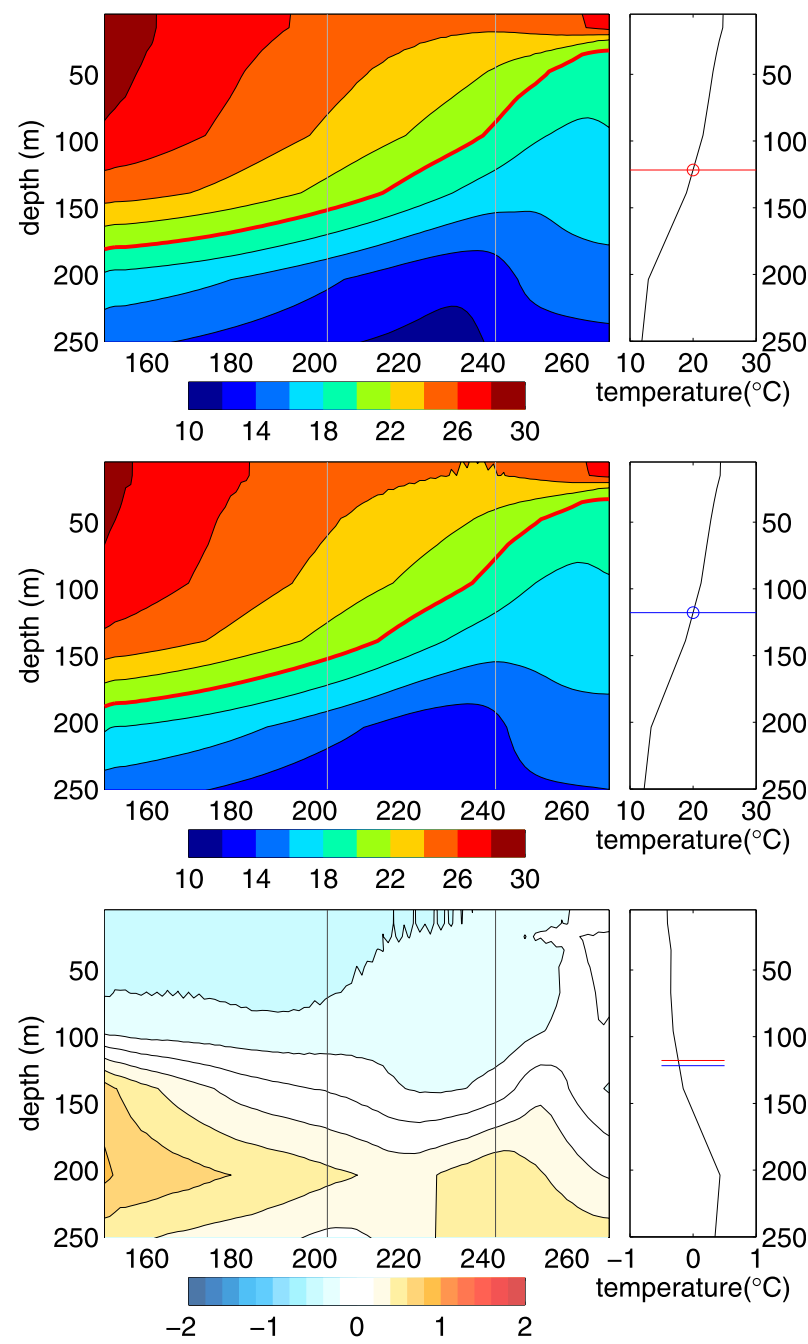

FIG. 8. As in Fig. 2, but for the HadCM3 simulations: (top) HadCM $p$ and (middle) HadCM6; (bottom) the difference, HadCM6 - HadCM $p$ (contour interval $0.2^{\circ} \mathrm{C}$ ). Also shown in the right panels is the location of $20^{\circ} \mathrm{C}$ isotherm in in the modern (red) and 6-ka (blue) simulations.

atmospheric drag coefficient and the subsurface ocean parameters on the modern-day data and use these values in all subsequent runs. We force all models with identical white noise and examine the spatiotemporal structure of the variance in each model. For brevity, however, we only show results for the change in the variance of Niño-3 and changes in the ENSO mode statistics because, unlike CSM, there is no change in the spatial structure of either the ENSO mode or the EOFs in stochastically forced runs of LOAM.

LOAM with the modern-day mean fields features a dynamical ENSO mode that has a period of $3.51 \mathrm{yr}$ and decay rate of $0.40 \mathrm{yr}^{-1}$. LOAM fitted with the midHolocene mean states $\left(\mathrm{LOAM}_{h}\right)$ features an ENSO mode similar in structure to that obtained from LOAM $p_{h}$
TABLE 3. ENSO statistics from the HadCM3 modern-day $(\operatorname{HadCM} p)$ and mid-Holocene (HadCM6) simulations and from LOAM using the mean state fields from the two aforementioned HadCM3 simulations (LOAM $p_{h}$ and $\mathrm{LOAM}_{h}$ ). The top rows show ENSO statistics from the HadCM3 modern-day (HadCMp) and mid-Holocene (HadCM6) simulations and from LOAM using the climatological fields from the two aforementioned HadCM3 simulations ( $\mathrm{LOAM} p_{h}$ and LOAM6h). Subsequent rows are from LOAM and use a mixture of early Holocene and modern mean states. See caption to Table 2 for further explanation of the table entries.

\begin{tabular}{lccc}
\hline \hline \multicolumn{1}{c}{ Model } & $\begin{array}{c}\text { Variance/ } \\
\text { (modern-day } \\
\text { variance) }\end{array}$ & $\begin{array}{c}\text { Mode } \\
\text { period }(\mathrm{yr})\end{array}$ & $\begin{array}{c}\text { Mode } \\
\text { decay } \\
\left(\mathrm{yr}^{-1}\right)\end{array}$ \\
\hline HadCM $p$ & 1.00 & & \\
HadCM6 & 0.82 & & \\
LOAM $p_{h}$ & 1.00 & 3.51 & 0.40 \\
LOAM ${ }_{h}$ & 0.66 & 3.75 & 0.33 \\
LOAM $p_{h}+$ ocn & 0.70 & 3.68 & 0.35 \\
LOAM $p_{h}+$ curr & 0.84 & 3.52 & 0.39 \\
LOAM $p_{h}+$ upwell & 0.97 & 3.63 & 0.37 \\
LOAM $p_{h}+T_{z}$ & 1.00 & 3.53 & 0.40 \\
LOAM $p_{h}+\Gamma$ & 0.82 & 3.62 & 0.36 \\
LOAM $p_{h}+$ horizcurr & 0.85 & 3.36 & 0.41 \\
LOAM $p_{h}+\Gamma+$ horizcurr & 0.70 & 3.47 & 0.36 \\
LOAM $p_{h}+$ atm & 0.93 & 3.55 & 0.38 \\
LOAM $p_{h}+$ SST & 0.95 & 3.63 & 0.38 \\
\hline
\end{tabular}

with a period that is slightly longer $(3.75 \mathrm{yr})$ and more damped $\left(0.33 \mathrm{yr}^{-1}\right)$ than that from LOAM $p_{h}$.

Comparing the variance of the Niño-3 index from $\mathrm{LOAM} p_{h}$ and LOAM6 ${ }_{h}$, we find the variance of ENSO is reduced at $6 \mathrm{ka}$ compared to the modern climate by $34 \%$, which is larger than the $18 \%$ reduction in the variance of Niño-3 seen in the 6-ka HadCM3 simulation compared to the modern-day HadCM3 simulation (see Table 3). Hence, as for the CSM integrations, the reduction of variance in ENSO in the HadCM3 integrations appears to be due to changes in the mean state in the tropical Pacific. We note, however, that there also must be a change in the amplitude or structure of the stochastic forcing in the HadCM3 integrations that tempers the reduction in variance that is due to the changes in the mean state. In the next section, we identify the mean state changes that are responsible for the reduction in ENSO variance.

\section{d. Diagnosis of the important mean state changes using LOAM}

In this section, we perform experiments with LOAM and the HadCM3 mean states to illuminate the important mean state changes for reducing the variance in ENSO during the mid-Holocene in HadCM3: the mean ocean stratification and the horizontal currents. Results from all of the LOAM experiments with partial HadCM3 fields and parameters are summarized in Table 3. 
We first insert the ocean mean states from the midHolocene HadCM3 simulation into LOAM but keep all other mean fields set to those from the modern HadCM3 simulation. The resulting model, called $\mathrm{LOAM} p_{h}+$ ocn, features an ENSO mode that has a slightly longer period $(3.68 \mathrm{yr})$ and a slightly greater decay rate $\left(0.35 \mathrm{yr}^{-1}\right)$ than that in $\operatorname{LOAM} p_{h}$. When $\operatorname{LOAM} p_{h}+$ ocn is run forward in time with the same stochastic forcing as was used in $\operatorname{LOAM} p_{h}$ (and all other LOAM runs using HadCM3 fields), the variance of the Niño-3 index is reduced to $70 \%$ of the modern value. These results are very similar to $\mathrm{LOAM}_{h}$ and, therefore, suggest that the change in ENSO at $6 \mathrm{ka}$ is due to the changes in the ocean. We diagnose which ocean mean states are responsible for this reduction in variance by first replacing the modern-day ocean currents with their mid-Holocene counterparts in LOAM $p_{h}+$ curr. The change in the variance of Niño-3 in this experiment is roughly half that in $\mathrm{LOAM}_{h}$ and is mainly due to changes in horizontal currents (see LOAM $p_{h}+$ horizcurr): changes in mean upwelling ( $\mathrm{LOAM} p_{h}+$ upwell) have a negligible impact on the variance in ENSO. We see, in Fig. 7, that at 6 ka the zonal currents are weaker compared to the modern day. This reduces the Bjerknes feedback by reducing the anomalous zonal advection that results from a unit of atmospheric wind stress anomaly, thereby stabilizing the ENSO mode.

Next, we examine how the changes in the vertical structure of the ocean impact ENSO variance. We recall that there are two parameterizations, $T_{z}$ and $\Gamma$, that affect the heating of the mixed layer: $T_{z}$ is the climatological temperature gradient at the base of the mixed layer, which affects the efficiency with which upwelling entrains water into the mixed layer, and $\Gamma$ relates temperature anomalies at the base of the mixed layer to movements in the thermocline. We first construct a LOAM model in which all parameterization and mean fields are identical to those in LOAM $p_{h}$ except the mean temperature difference $T_{z}$ at the base of the mixed layer, $\mathrm{LOAM} p_{h}+T_{z}$. Compared to LOAM $p_{h}$ there is little difference in the ENSO mode associated with changes in $T_{z}$, and there is no difference in the variance of ENSO when $\operatorname{LOAM} p_{h}+T_{z}$ is stochastically forced. Therefore, changes in $T_{z}$ are not responsible for the reduction in ENSO variance. Changing only the subsurface parameterization $\Gamma$ to be that from the mid-Holocene $\left(\mathrm{LOAM} p_{h}+\Gamma\right)$, we find that the period of the ENSO mode is lengthened slightly to $3.62 \mathrm{yr}$, and the decay rate increases to $0.36 \mathrm{yr}^{-1}$ compared to those in LOAM $p_{h}$. When $\operatorname{LOAM} p_{h}+\Gamma$ is stochastically forced, the variance in Niño-3 is reduced to 0.82 of that from the stochastically forced LOAM $p_{h}$. Plotted in Fig. 8 is the vertical structure of the ocean temperature along the equator. The mid-Holocene simulation features cooling of the upper $100 \mathrm{~m}$ and warming of the water below the thermocline. This weakening of the thermocline reduces the amplitude of subsurface temperature anomalies that arise from movements in the thermocline: these are determined by $\Gamma$. This, therefore, increases the stability of the ENSO mode.

Experiments $\mathrm{LOAM} p_{h}+$ curr and $\mathrm{LOAM} p_{h}+\Gamma$ suggest that, compared to the modern-day HadCM3 simulation, the variance in ENSO in the mid-Holocene is reduced in roughly an equal amount by changes in the horizontal currents and the vertical temperature structure of the ocean $(\Gamma)$. To test whether these two processes alone can account for the decrease in the variance in the mid-Holocene HadCM3 simulation, we run an experiment that includes changes only in $\Gamma$ and the horizontal currents, $\mathrm{LOAM} p_{h}+\Gamma+$ horizcurr. We find that the combined effect reduces the variance of Niño-3 to 0.70 of that in $\operatorname{LOAM} p_{h}$. This accounts for nearly all of the changes in ENSO variance that result from changes in the mean state of the ocean (i.e., the ENSO behavior of $\operatorname{LOAM} p_{h}+\Gamma+$ horizcurr is very similar to that of LOAM $p_{h}+$ ocn).

To illuminate the impact of atmospheric mean state changes we create $\mathrm{LOAM} p_{h}+$ atm, which comprises modern-day mean states and parameters in the ocean and the mid-Holocene mean winds and SST in the atmosphere. $\mathrm{LOAM} p_{h}+$ atm features an ENSO mode with a period and decay rate that are little changed compared to the modern LOAM $p_{h}$ values. The variance in Niño-3 from the stochastically forced LOAM $p_{h}+$ atm is very similar to that from LOAM $p_{h}$. For completeness we also create LOAM $p_{h}+$ SST, which has all of the mean fields and parameters from the modern HadCM3 except for the SST that the atmosphere sees, which is from the $6 \mathrm{ka}$ run of HadCM3. Table 3 shows that the ENSO mode in LOAM $p_{h}+$ SST has a period and decay rate very similar to that from $\operatorname{LOAM} p_{h}$, and the variance of the Niño-3 index is little changed from LOAM $p_{h}$. Therefore, unlike in the CSM, changes in the response of the atmosphere to SST anomalies do not affect the variance in ENSO in the mid-Holocene.

\section{Discussion of the results}

In this section, we compare the mechanism for ENSO stabilization in the CSM and HadCM3 climate models that we have isolated quantitatively using LOAM to various hypotheses in the literature.

Clement et al. (2000) imposed a cyclostationary forcing on the ZCM ocean to account for the changes in insolation throughout the Holocene and examined the change in ENSO activity in that model. They concluded 
that ENSO activity was reduced in the ZCM because changes in the strength and seasonality of the trade winds created an unfavorable environment for the growth of an incipient ENSO event in the early Holocene compared to the modern day. In particular, they argued that stronger trade winds in late summer inhibit the growth of ENSO by reducing the amplitude of the westerly wind stress anomalies associated with the growing ENSO event and, thus, altering the mix of processes that govern the response of the ocean to a canonical surface stress perturbation.

Otto-Bliesner et al. (2003) and Braconnot et al. (2011) noted that the seasonality of the climatological trade winds in the early Holocene model simulation was different from that in the modern-day simulations and that the differences were similar to those reported by Clement et al. (2000). On the basis of these similarities they hypothesized that the changes in the seasonality of the trades in their simulations were responsible for the reduction in ENSO variance in the early Holocene, invoking the same argument as Clement et al. (2000). Our analysis of the output from these two experiments using LOAM demonstrates that this is likely not the case. In isolation, changes in the climatological trades (cf. LOAM $p$ and LOAM $p+\tau_{\text {atm }}$ ) and in the seasonality of the winds $\left[\operatorname{LOAM} p+\operatorname{cyc}\left(T_{\mathrm{atm}}\right)\right]$ both act to slightly increase the variance of ENSO. This is because the ocean's response to a canonical zonal wind anomaly is greater for a greater climatological wind stress.

LOAM shows that ENSO variance is reduced in the early Holocene in the CSM because the mean state SST is decreased (cf. LOAM $p$ and LOAM $p+T_{\text {atm }}$ ). At 8.5 ka the mean SST modeled by CSM is colder than in the modern-day run, which results in atmospheric heating anomalies that are smaller. This then leads to a weaker wind stress response to SST anomalies and, thus, reduces the coupling between the atmosphere and the ocean. LOAM also shows that at $8.5 \mathrm{ka}$ the ocean mean states support a less stable ENSO mode because of a shoaling of the thermocline that increases the SST response to movements in the thermocline; ocean mean state changes are also responsible for an eastward shift of the center of action, which lengthens the period of the ENSO mode. Therefore, when taken in isolation, the changes in the ocean and atmosphere mean states render the ENSO mode less and more stable, respectively; when all mean state changes are taken together, the ENSO mode becomes more stable.

Why do the changes in the trade winds act to amplify the variance of ENSO in LOAM with CSM mean states yet decrease it in the ZCM? One possibility is that there are differences in the changes in the trades in these two models that are important for ENSO; these differences are inevitable because changes in the trades in the ZCM are solely due to coupled atmosphere interactions in the tropical Pacific, while in the GCMs they are due to the global response to insolation forcing-including the response of the monsoons. However, a more likely source for the different response is a fundamental difference in the actual question that the model configurations answered. By incorporating mean state data into LOAM we ask the question: for a given mean state in the tropical Pacific how does ENSO behave? The question as posed by Clement et al. (2000) is: how does ENSO respond to an anomalous seasonally varying surface heating in the tropical Pacific? Although an anomalous, seasonally varying heating will result in a change in the mean state in the ZCM, this change manifests itself as a systematic time-averaged change in the anomaly fields calculated by the model-the very same anomaly fields that describe the evolution of ENSO. Therefore, the model does not describe how ENSO changes in response to a change in the mean state. Roberts (2007) used the $\mathrm{ZCM}^{2}$ to examine the seasonality hypothesis and found ENSO variance is reduced in the early Holocene because of a nonlinear saturation in the model's equation for subsurface temperature: linearizing about the early Holocene climate simulated by the ZCM (treating a change in the mean of the anomalies as a change in the mean state), the ENSO mode is actually more unstable in the early Holocene than in the modern climate in the ZCM.

Brown et al. (2008), in analyzing the mid-Holocene and modern-day simulations using the HadCM3 model, also noted changes in the climatological trade winds in the early Holocene that were similar to those found in the ZCM, so they too hypothesized that the changes in the seasonality of the trades were responsible for the reduction in ENSO variance in the mid-Holocene in the HadCM3 simulations. Again, this hypothesis was made on the basis of observed similarities between mean states: it was not diagnosed. LOAM shows that, to the contrary, ENSO activity in HadCM3 is reduced in the mid-Holocene because the mean zonal currents become weaker and the thermocline in the model becomes more diffuse. For a canonical wind stress anomaly, this reduces the amplitude of SST anomalies generated by anomalous advection acting on the zonal mean SST gradient and reduces the SST anomalies produced by movements in the thermocline. Therefore, the ENSO mode is stabilized by reducing the amplitude of the Bjerknes feedback.

Finally, a more recent study by Chiang et al. (2009) shows that it is possible to explain the reduction in

\footnotetext{
${ }^{2}$ The version of the ZCM described in Battisti (1988).
} 
ENSO activity by changes to the noise that forces ENSO. Their coupled model is constructed so that the mean state in the tropical Pacific cannot change; thus, any change in ENSO variance is entirely because of changes in the stochastic forcing. They identify the dominant source of this stochastic forcing in their model as the seasonal footprinting mechanism (SFM) (Vimont et al. 2003). In a follow-up, Chiang and Fang (2010) showed that a change in the strength of the atmospheric eddies in the wintertime North Pacific is responsible for the reduced stochastic forcing by the SFM in their 6-ka run. Since the SFM is the dominant source of stochastic forcing in observations and in some models (e.g., Chiang et al. 2009), we examined the early/mid-Holocene and modernday simulations from the CSM and HadCM3 models for evidence of a change in the SFM.

In the CSM we found no significant change in the SFM, which is consistent with the results from LOAM: they showed that the mean state changes alone can explain the change in ENSO variance. In HadCM3 we also found no significant change in the SFM. Since our experiments with LOAM indicate that the changes in the mean state in HadCM3 should have caused a much greater reduction in the variance of ENSO during the mid-Holocene, this suggests that there is a net decrease in the amplitude or efficiency of the stochastic forcing of ENSO compared to the modern day. As there is no change in the amplitude of the SFM forcing, the source of the differences in stochastic forcing must lie elsewhere.

\section{Conclusions and implications}

The spatiotemporal structure of ENSO is extremely sensitive to the structure of the mean state of the atmosphere and upper ocean in the tropical Pacific (Zebiak 1985; Battisti and Hirst 1989; Thompson and Battisti 2001; Neelin et al. 1998; Penland and Sardeshmukh 1995), as well as to uncoupled stochastic weather forcing. Changes in external forcing will cause changes in the climatological distribution of SST, ocean currents, thermocline depth, and surface wind, and so on-each of which affects the spatiotemporal characteristics of ENSO. Hence, it is a daunting challenge to understand how and why ENSO will change when there is a change in the forcing of the climate system (e.g., greenhouse gas concentration or insolation) - whether it be from proxy observations of the mean state or a high-end atmosphereocean climate model.

Here we demonstrate that a new offline tool, called LOAM, can be used to understand the impact of the (changing) mean state of the atmosphere-ocean system in the tropical Pacific on the spatiotemporal variability of ENSO. We apply LOAM to the modern-day and
early/mid-Holocene simulations that were previously performed using the HadCM3 and CSM climate models [see Brown et al. (2008) and Otto-Bliesner et al. (2003), respectively]. We show that, when the mean fields from the modern-day and early/mid-Holocene simulations are inserted into LOAM, LOAM reproduces the spatiotemporal variability simulated by the climate models, including reduction in the variance of ENSO in the tropical Pacific. The leading eigenmode (Floquet mode) of LOAM is recognizably the ENSO mode found in each of the climate model simulations, and therefore the changes in the spatial structure of the variance are also captured by LOAM. We show that in both of these climate models, the variance of ENSO in the early Holocene is reduced compared to their respective modern-day simulation because of the impacts of the mean state changes on the structure (CSM) and stability (HadCM3) of the ENSO mode.

Interestingly, the mean state changes responsible for stabilizing the ENSO mode in the CSM are entirely different from those that are important for stabilizing the ENSO mode in the HadCM3 model. By swapping the isolated mean state variables from the early Holocene into and out of LOAM (with otherwise modernday mean fields), we show that the ENSO mode in the CSM model is stabilized in the early Holocene because the mean state SST is reduced compared to the modernday simulation. This reduces the atmospheric response to a canonical SST anomaly through the relationship between water vapor and SST via the Clausius-Clapeyron dependence with fixed surface relative humidity, thus weakening the Bjerknes feedback. In contrast, analogous experiments using LOAM and the mean state fields from the HadCM3 model show that the ENSO mode is stabilized in the mid-Holocene simulation because the zonal currents and thermocline along the equator are weaker than in the modern simulation. This reduces the response of the ocean to a canonical wind stress anomaly, thus weakening the Bjerknes feedback.

The profound differences in the impact of the mean state changes in these two models is further illustrated by considering the impact of the (isolated) ocean mean state changes on ENSO. In HadCM3 the changes in the mean state ocean during the mid-Holocene are the key to stabilizing the ENSO mode and reducing the ENSO variance, while in the CSM the ocean mean state changes, when considered in isolation, greatly destabilize the ENSO mode. Conversely, when considering the atmosphere in isolation, the changes in the mean state lead to a dramatic increase in the stability of the ENSO mode in CSM, whereas they have a negligible impact on HadCM3. Furthermore, changes in the ocean mean state have no impact on the structure of the variability in 
the HadCM3 simulation, while in the CSM the ocean mean state changes greatly affect the spatial structure and period of the ENSO mode, thus the pattern of tropical variability.

A number of gross metrics and simple model fits have been proposed to categorize the nature of ENSO in models (e.g., Jin et al. 2006; Guilyardi 2006; Lloyd et al. 2009; Guilyardi et al. 2009, and references therein). Our analysis of the CSM and HadCM3 climate model simulations using LOAM illustrates the importance of performing an analysis of the full mean state changes when evaluating the impact of forcing on the variability of ENSO. They also illustrate the danger in applying intuition, gross metrics, and simple models for evaluating why ENSO changes in a climate model. For example, the processes that turn out to be most important for the reduction of ENSO in both of the climate models examined in this paper differ from those hypothesized, but not diagnosed, in the papers that first described these GCM simulations (cf. the last two columns in Table 1). To unambiguously discern how ENSO responds to forcing, theory, and the results from this study starkly demonstrate the importance of using either cleverly designed, expensive (and illusive) experiments with full climate models or an analysis of the climate model output with an offline model, such as LOAM, that takes into account the full changes in all of the mean state fields, including the important spatial structure in the mean fields (e.g., the rich two-dimensional structure in SST that is so important for the atmospheric response to an SST anomaly). Of course, the utility of LOAM is limited to analyzing GCMs that support variability in the tropical Pacific that is well described by linear physics, such as the CSM and HadCM3 models (and the observations).

We have shown that this system for calculating mean states from GCM output and incorporating them into LOAM can yield insights into the coupled response of ENSO to mean state changes. It is, therefore, hoped that this tool will be widely used to further our understanding of ENSO in both nature and in models. For example, we can use the tool to investigate how ENSO will respond to the projected increase in greenhouse gases or to changes in forcing further back in time, such as in the Pliocene. The model can also be used to diagnose the impact of mean state biases on the ENSO supported by a climate mode.

Why was ENSO actually reduced in the early Holocene in comparison to the modern climate? This might be an unanswerable question. We have described how two climate models reduce the ENSO variance by way of mean state changes that stabilize the ENSO mode in the early/mid-Holocene compared to the modern day.
We found that they did so for entirely different reasons. Unfortunately, it will be difficult to evaluate the veracity of either of the two models using proxy data because the mean-state SST changes that stabilize the ENSO mode in the CSM are modest compared to the uncertainty in proxy indicators of SST, and we do not have proxy data of the structure of the thermocline along the equator, a quantity that was important to both HadCM3 and CSM. Furthermore, Cobb et al. (2013) present results that indicate the variance of ENSO throughout much of the Holocene (from 7000 ka to AD 1500) was consistently reduced compared to the last 400 or so years. This suggests that the variance of ENSO may also be affected by processes other than orbitally forced mean state changes, processes that are as yet unknown.

Acknowledgments. Thanks to Bette Otto-Bleisner, Mat Collins, and Jo Brown for kindly sharing the output from their model runs and to John Chiang and Dan Vimont for many fruitful discussions. This work was supported, in part, by a grant from the Ocean and Atmosphere Research (OAR) Climate Program Office (CPO) of the National Oceanic and Atmospheric Administration (NA08OAR4310883).

\section{REFERENCES}

Battisti, D. S., 1988: Dynamics and thermodynamics of a warming event in a coupled tropical atmosphere ocean model. J. Atmos. Sci., 45, 2889-2919.

— atmosphere-ocean model: Influence of the basic state, ocean geometry and nonlinearity. J. Atmos. Sci., 46, 1687-1712.

Braconnot, P., Y. Luan, S. Brewer, and W. Zheng, 2011: Impact of Earth's orbit and freshwater fluxes on Holocene climate mean seasonal cycle and ENSO characteristics. Climate Dyn., 38, 1081-1092, doi:10.1007/s00382-011-1029-x.

Brown, J., M. Collins, and A. Tudhope, 2006: Coupled model simulations of mid-Holocene ENSO and comparisons with coral oxygen isotope records. Adv. Geosci., 6, 29-33.

,,,--- and T. Toniazzo, 2008: Modelling mid-Holocene tropical climate and ENSO variability: Towards constraining predictions of future change with palaeo-data. Climate Dyn., 30, 19-36, doi:10.1007/s00382-007-0270-9.

Chiang, J. C. H., and Y. Fang, 2010: Was the North Pacific wintertime climate less stormy during the mid-Holocene? J. Climate, 23, 4025-4037.

,-- , and P. Chang, 2009: Pacific climate change and ENSO activity in the mid-Holocene. J. Climate, 22, 923-939.

Clement, A. C., R. Seager, and M. A. Cane, 2000: Suppression of El Niño during the mid-Holocene by changes in the earth's orbit. Paleoceanography, 15, 731-737.

Cobb, K. M., N. Westphal, H. R. Sayani, J. T. Watson, E. Di Lorenzo, H. Cheng, R. L. Edwards, and C. D. Charles, 2013: Highly variable El Niño-Southern Oscillation throughout the Holocene. Science, 339, 67-70, doi:10.1126/science.1228246.

Collins, M., 2000: Understanding uncertainties in the response of ENSO to greenhouse warming. Geophys. Res. Lett., 27 (21), 3509-3512. 
- S. Tett, and C. Cooper, 2001: The internal climate variability of HadCM3, a version of the Hadley Centre coupled model without flux adjustments. Climate Dyn., 17, 61-81.

Guilyardi, E., 2006: El Niño-mean state-seasonal cycle interactions in a multi-model ensemble. Climate Dyn., 26, 329-348, doi:10.1007/s00382-005-0084-6.

—, A. Wittenberg, A. V. Fedorov, M. Collins, C. Wang, A. Capotondi, G. J. van Oldenborgh, and T. Stockdale, 2009: Understanding El Niño in ocean-atmosphere general circulation models: Progress and challenges. Bull. Amer. Meteor. Soc., 90, 325-340

Jin, F.-F., S. T. Kim, and L. Bejarano, 2006: A coupled-stability index for ENSO. Geophys. Res. Lett., 33, L23708, doi:10.1029/ 2006GL027221.

Johnson, S. D., D. S. Battisti, and E. S. Sarachik, 2000: Empirically derived Markov models and prediction of tropical Pacific sea surface temperature anomalies. J. Climate, 13, 3-17.

Kaplan, A., M. Cane, Y. Kushnir, A. Clement, M. Blumenthal, and B. Rajagopalan, 1998: Analyses of global sea surface temperature 1856-1991. J. Geophys. Res., 103 (C9), 18 567-18589.

Koutavas, A., P. B. deMenocal, G. C. Olive, and J. Lynch-Stieglitz, 2006: Mid-Holocene El Niño-Southern Oscillation (ENSO) attenuation revealed by individual foraminifera in eastern tropical Pacific sediments. Geology, 34, 993-996, doi:10.1130/ G22810A.1.

Liu, Z., 2002: A simple model study of ENSO suppression by external periodic forcing. J. Climate, 15, 1088-1098.

_ J. Kutzbach, and L. Wu, 2000: Modeling climatic shift of El Niño variability in the Holocene. Geophys. Res. Lett., 27, 2265-2268.

_- E. Brady, and J. Lynch-Stieglitz, 2003: Global ocean response to orbital forcing in the Holocene. Paleoceanography, 18, 1041, doi:10.1029/2002PA000819.

Lloyd, J., E. Guilyardi, H. Weller, and J. Slingo, 2009: The role of atmosphere feedbacks during ENSO in the CMIP3 models. Atmos. Sci. Lett., 10, 170-176.

Neelin, J., D. S. Battisti, A. Hirst, F. Jin, Y. Wakata, T. Yamagata, and S. Zebiak, 1998: ENSO theory. J. Geophys. Res., 103 (C7), 14261-14290

North, G. R., T. Bell, R. Cahalan, and F. Moeng, 1982: Sampling errors in the estimation of empirical orthogonal functions. Mon. Wea. Rev., 110, 699-706.

Otto-Bliesner, B. L., and E. C. Brady, 2001: Tropical Pacific variability in the NCAR Climate System Model. J. Climate, 14, 3587-3607.
——, S. Shin, Z. Liu, and C. Shields, 2003: Modeling El Niño and its tropical teleconnections during the last glacial-interglacial cycle. Geophys. Res. Lett., 30, 2198, doi:10.1029/2003GL018553.

Penland, C., and P. D. Sardeshmukh, 1995: The optimal-growth of tropical sea surface temperature anomalies. J. Climate, $\mathbf{8}$, 1999-2024.

Roberts, W. H. G., 2007: An investigation into the causes for the reduction in the variability of the El Niño-Southern Oscillation in the early Holocene in a global climate model. Ph.D. thesis, University of Washington, $145 \mathrm{pp}$.

_ and D. S. Battisti, 2011: A new tool for evaluating the physics of coupled atmosphere-ocean variability in nature and in general circulation models. Climate Dyn., 36, 907-923, doi:10.1007/s00382-010-0762-x.

Seager, R., S. E. Zebiak, and M. A. Cane, 1988: A model of the tropical Pacific sea surface temperature climatology. J. Geophys. Res., 93 (C2), 1265-1280.

Thompson, C. J., and D. S. Battisti, 2000: A linear stochastic dynamical model of ENSO. Part I: Model development. J. Climate, 13, 2818-2832.

—, and —, 2001: A linear stochastic dynamical model of ENSO. Part II: Analysis. J. Climate, 14, 445-466.

Timmermann, A., F.-F. Jin, and J. Abrshagen, 2003: A nonlinear theory for El Niño bursting. J. Atmos. Sci., 60, 152-165.

Tudhope, A. W., and Coauthors, 2001: Variability in the El NiñoSouthern Oscillation through a glacial-interglacial cycle. Science, 291, 1511-1517, doi:10.1126/science.1057969.

Vimont, D. J., J. M. Wallace, and D. S. Battisti, 2003: The seasonal footprinting mechanism in the Pacific: Implications for ENSO. J. Climate, 16, 2668-2675.

Wang, B., and S. An, 2002: A mechanism for decadal changes of ENSO behavior: Roles of background wind changes. Climate Dyn., 18, 475-486, doi:10.1007/s00382-001-0189-5.

Zebiak, S. E., 1985: Tropical atmosphere-ocean interaction and the El Niño/Southern Oscillation phenomenon. Ph.D. thesis, Massachusetts Institute of Technology, $261 \mathrm{pp}$

_ 1986: Atmospheric convergence feedback in a simple model for El Niño. Mon. Wea. Rev., 114, 1263-1271. , and M. A. Cane, 1987: A model El Niño-Southern Oscillation. Mon. Wea. Rev., 115, 2262-2278.

Zheng, W., P. Braconnot, E. Guilyardi, U. Merkel, and Y. Yu, 2008: ENSO at $6 \mathrm{ka}$ and $21 \mathrm{ka}$ from ocean-atmosphere coupled model simulations. Climate Dyn., 30, 745-762, doi:10.1007/ s00382-007-0320-3. 